\title{
Analysis of RF Front-End Performance of Reconfigurable Antennas with RF Switches in the Far Field
}

\author{
Insu Yeom, ${ }^{1}$ Junghan Choi, ${ }^{2}$ Sung-su Kwoun, ${ }^{3}$ Byungje Lee, ${ }^{4}$ and Changwon Jung ${ }^{1}$ \\ ${ }^{1}$ Graduate School of NID Fusion Technology, Seoul National University of Science and Technology, Seoul 139-743, Republic of Korea \\ ${ }^{2}$ Fraunhofer Institute for Telecommunications, Heinrich-Hertz Institute, Einsteinufer 37, 10587 Berlin, Germany \\ ${ }^{3}$ Department of Radiological Science, Gachon University, 191 Hambakmoe-ro, Yeonsu-gu, Inchon 406-799, Republic of Korea \\ ${ }^{4}$ Department of Wireless Communications Engineering, Kwangwoon University, 447-1 Wolgye-dong, Nowon-gu, \\ Seoul 139-701, Republic of Korea
}

Correspondence should be addressed to Changwon Jung; changwoj@snut.ac.kr

Received 25 November 2013; Accepted 20 January 2014; Published 4 March 2014

Academic Editor: Michael Yan Wah Chia

Copyright (C) 2014 Insu Yeom et al. This is an open access article distributed under the Creative Commons Attribution License, which permits unrestricted use, distribution, and reproduction in any medium, provided the original work is properly cited.

\begin{abstract}
The RF front-end performances in the far-field condition of reconfigurable antennas employing two commonly used RF switching devices (PIN diodes and RF-MEMS switches) were compared. Two types of antennas (monopole and slot) representing general direct/coupled feed types were used for the reconfigurable antennas to compare the excited RF power to the RF switches by the reconfigurable antenna types. For the switching operation of the antennas, a biasing circuit was designed and embedded in the same antenna board, which included a battery to emphasize the antenna's adaptability to mobile devices. The measurement results of each reconfigurable antenna (radiation patterns and return losses) are presented in this study. The receiving power of the reference antenna was measured by varying the transmitting power of the reconfigurable antennas in the far-field condition. The receiving power was analyzed using the "Friis transmission equation" and compared for two switching elements. Based on the results of these measurements and comparisons, we discuss what constitutes an appropriate switch device and antenna type for reconfigurable antennas of mobile devices in the far-field condition.
\end{abstract}

\section{Introduction}

The rapid development of electronics and wireless communication has led to great demand for mobile devices that can operate across various broadcasting, voice, and Internet standards. In addition, most consumers also now demand smaller form factors for their mobile devices. These requirements have triggered research on the design of compact and multiband antennas [1-4]. Single-antenna elements with a single-feed port that can operate over multiple frequency bands have mainly been implemented using wide-band or multiband antenna techniques [1-4]. However, these antenna techniques require increased volume and have low radiation efficiency compared with single-antenna elements for singleband operation. In addition, wide-band antennas generally have higher-mode beams, which are not desired in omnidirectional communication environments within operational frequency bands [4]. To operate multiple-frequency bands with an improved radiation efficiency and pattern, frequency reconfigurable antennas have recently been introduced. However, their use of RF switches, such as diodes and MEMS switches, means that they suffer from radiation losses [512]. Frequency reconfigurable antennas use their application bands separately; therefore, they have better radiation efficiency and can also be made to have omni-directional radiation patterns instead of higher mode beams [5-12].

Reconfigurable antennas have received significant attention for their applications in communications, electronic surveillance, and countermeasures, and their properties have been adapted to achieve selectivity in frequency, bandwidth, polarization, and gain. This can result in a significant reduction in the overall size of multimode, multiband wireless communication systems and replace multiple single-function legacy antennas. Also, the properties of reconfigurable antennas can be used as important allowances in an adaptive system [13-19]. However, the RF-front end performance in 


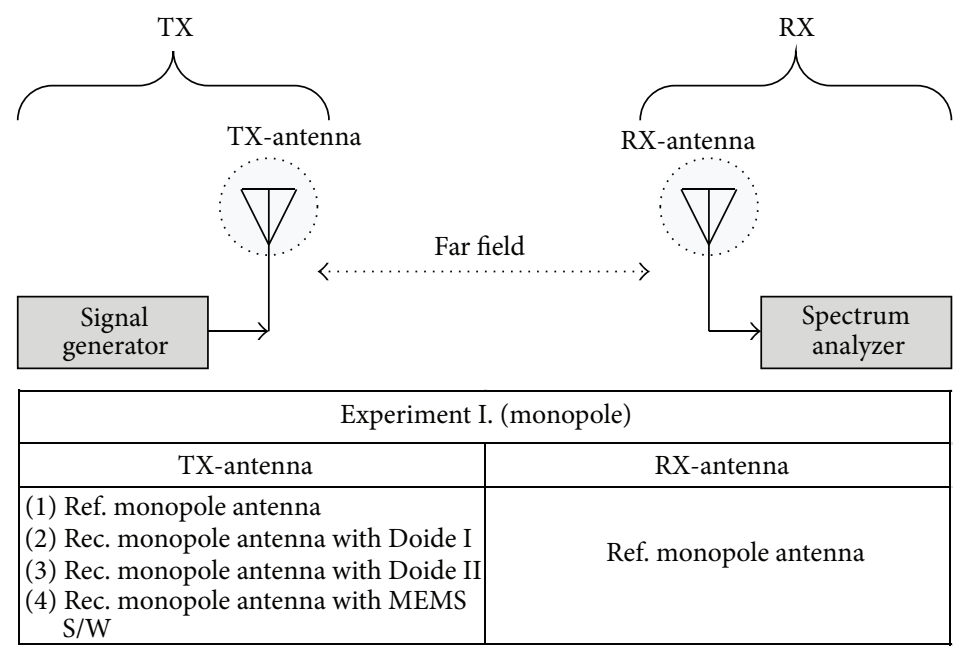

\begin{tabular}{|l|c|}
\hline \multicolumn{2}{|c|}{ Experiment II. (slot) } \\
\hline \multicolumn{1}{|c|}{ TX-antenna } & RX-antenna \\
\hline (1) Ref. slot antenna & \\
(2) Rec. slot antenna with Doide I & Ref. slot antenna \\
(3) Rec. slot antenna with Doide II & \\
(4) Rec. slot antenna with MEMS S/W & \\
\hline
\end{tabular}

FIGURE 1: RF performance analysis of reconfigurable antennas with RF switches in the far-field condition.

the far-field condition of reconfigurable antennas employing various RF switching devices has not been experimentally analyzed. This is one of a number of important issues in realizing practical applications of reconfigurable antennas in the wireless communication environment. It is expected that $\mathrm{RF}$ features such as the receiving power level, the power linearity, the power rating, and the radiation pattern of reconfigurable antennas will be affected by the RF switching element and the antenna types selected, especially in the commercial mobile environment.

RF switching devices such as PIN diodes and RF-MEMS switches are the basic building components for reconfigurable antennas. The RF switching is normally accomplished by using semiconductor devices such as diodes or field-effect transistors (FETs). Recently, PIN diodes have been used for the RF switching of a reconfigurable antenna for the purpose of multifrequency band operation $[5,6]$, beam steering [13-15], and dual-polarized radiation [19]. However, these semiconductor devices have a low $Q(Q<3 @ 10 \mathrm{GHz})$ at high frequencies and, therefore, exhibit high insertion loss [19]. In addition, PIN diodes consume significant amounts of power, typically greater than $25 \mathrm{~mW}$, in the low-loss ON-state, whereas RF-MEMS switches require nearly zero power to electrostatically hold the switch closed [20-22]. Thus, the use of RF-MEMS switches has provided a reliable alternative to semiconductor devices [7-12, 15-18]. The RF-MEMS switches have a high $Q(Q>10 @ 10 \mathrm{GHz})$ compared to the semiconductor devices [20-22]. Also, the RF-MEMS switch consumes virtually zero DC power at normal operation and only dissipates power during the switching transition. However, the RF-MEMS switches also have disadvantages such as high cost and low reliability. In addition, RF-MEMS switches generally require a very high bias voltage of $20 \sim 100 \mathrm{~V}$ for reliable switching operation. This requirement necessitates the use of a voltage upconverter chip in portable telecommunication systems. Although the RF performances of RF-MEMS switches are better than those of the PIN diodes, we cannot disregard the complexity of the biasing circuit. On the contrary, the PIN diodes need less complicated biasing components. Although they show higher insertion loss, there should be a tradeoff between the two RF switching elements. As mentioned above, there are conspicuous differences in the characteristics of PIN diodes and MEMS switches. Although we can estimate the electrical performance of the reconfigurable antennas using the datasheet of the switches, no detailed research is available about the reconfigurable antenna's performance in terms of the switch's and the antenna's structure, especially for the power handling capability and the linearity of the switches mounted in the antennas.

In this paper, we measured, compared, and analyzed the RF performances of reconfigurable antennas in the farfield condition by employing two types of representative antenna (monopole and slot) and two types of representative RF switches (a PIN diode and an MEMS switch). Figure 1 shows the conception diagram. First of all, we designed two types (a monopole and a slot) of reference antennas and four types of reconfigurable antenna (a monopole with PIN Diodes I and II, a monopole with an MEMS switch, a slot with PIN Diodes I \& II, and a slot with an MEMS switch) and measured each antenna's performance, including its radiation pattern and its reflection coefficient. The reference antennas were used as directly exited to the RF switch in the monopole antenna and were indirectly exited to the RF 
switch in the slot antenna due to the coupled feed use. This effect on the RF switch determined the power rating of the reconfigurable antenna depending on the antenna types. To analyze the electrical performance of the proposed antenna, we measured the receiving power of the reference antennas in the far-field condition $(2.5 \mathrm{~m})$ for various levels of transmitted power. The transmitted power of the reconfigurable antennas in the switch $O N$-state was up to $35 \mathrm{dBm}$, which is over $24 \mathrm{dBm}$ (power class 3) or $27 \mathrm{dBm}$ (typical cellular phone transmission power: power class 2) of the general maximum handling power of commercial mobile devices. The receiving power was calculated using the "Friis transmission equation" and compared with the measured results for the four types of reconfigurable antennas. The relation between the transmitted and the receiving power was also examined to check the linearity of the reconfigurable antennas. Based on these measurements and comparisons, we discuss what constitutes an appropriate switch device and antenna type for reconfigurable antennas in the far-field condition, especially for the mobile communication environment.

\section{Reference Antennas}

2.1. Antenna Configuration. Schematic diagrams of monopole and slot reference antennas representing direct/coupled feeds are shown in Figure 2. Both reference antennas were designed to measure their receiving power and to compare their performance only in the ON-state of reconfigurable antennas with RF switches because the RF switches do not work in the OFF-state. The antenna was printed on an FR-4 substrate with $1 \mathrm{~mm}$ thickness and relative permittivity $\left(\varepsilon_{r}\right)$ of 4.4. The size of the substrate of the monopole was $60 \mathrm{~mm}$ $\left(L_{m}\right) \times 30 \mathrm{~mm}\left(W_{m}\right)$. The ground plane length (GL) of the monopole in the bottom side was $30 \mathrm{~mm}$. The length of the monopole (AL) on the top side was $20 \mathrm{~mm}$ for the operating frequency of $2 \mathrm{GHz}$ when the switch was in the ON-state in the reconfigurable monopole antenna. Also, the size of the substrate of the slot antenna was $70 \mathrm{~mm}\left(L_{s}\right) \times 70 \mathrm{~mm}\left(W_{s}\right)$. The slot dimension on the bottom ground plane was $30.5 \mathrm{~mm}$ $(\mathrm{SL}) \times 2 \mathrm{~mm}(\mathrm{SW})$ to enable it to operate at $2.8 \mathrm{GHz}$, which is the frequency of the ON-state in the reconfigurable slot antenna. The length of the coupled feed line (FL) on the top side of the slot antenna was $36.4 \mathrm{~mm}$.

2.2. Simulation and Measurement Results. The simulated and measured reflection coefficients $\left(S_{11}\right)$ of the two reference antennas are shown in Figure 3. The $S_{11}$ of the antennas was less than $10 \mathrm{~dB}$ at $2 \mathrm{GHz}$ in the monopole antenna and at $2.8 \mathrm{GHz}$ in the slot antenna. The bandwidth $\left(10>S_{11}(\mathrm{~dB})\right)$ of the antennas was $350 \mathrm{MHz}(17.5 \%)$ for the monopole antenna and $150 \mathrm{MHz}(5.3 \%)$ for the slot antenna. Figure 4 shows simulated and measured radiation patterns in the reference plane ( $x z$-plane) at the operating frequencies of both antennas. As we expected, the overall pattern was omnidirectional. The maximum antenna gain was $2.4 \mathrm{dBi}$ for the monopole antenna and $4.7 \mathrm{dBi}$ for the slot antenna. The radiation efficiencies of the monopole antenna and the slot antennas were $97.3 \%$ and $90.2 \%$, respectively. The slot antenna

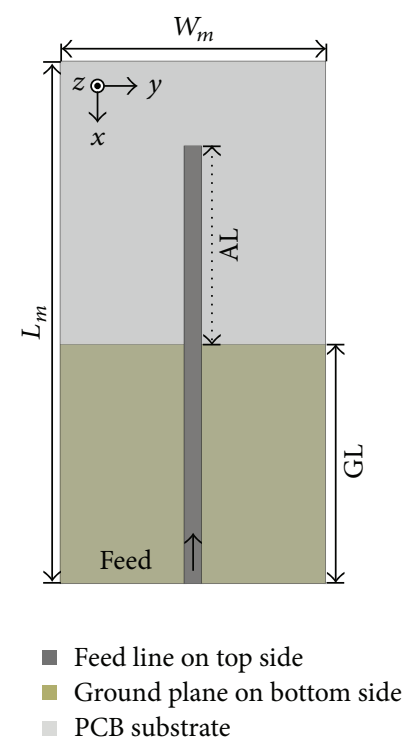

(a)

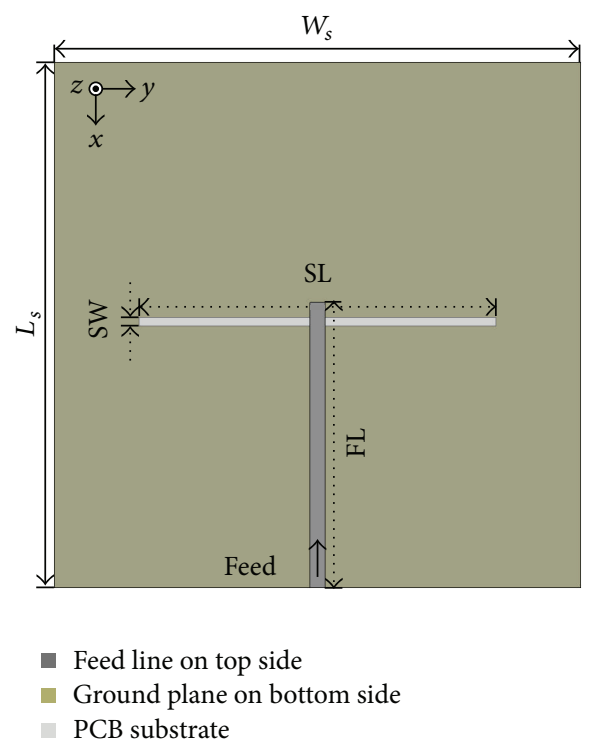

(b)

FIGURE 2: Geometry of the reference antennas; (a) the monopole antenna and (b) the slot antenna.

exhibited higher gain and lower efficiency than themonopole antenna because the radiation beam pattern of the slot antenna is directive. The attributes of the reference antennas, such as their measured radiation pattern, maximum gains, and efficiencies, satisfy the general characteristics of typical monopole and slot antennas in previous research [5].

\section{Reconfigurable Antennas with RF Switches}

3.1. Configuration of the Reconfigurable Antenna with PIN Diodes. We present two kinds of reconfigurable antennas (a monopole and a slot antenna) with RF switches (a PIN diode and an MEMS switch). Both antennas were designed on 


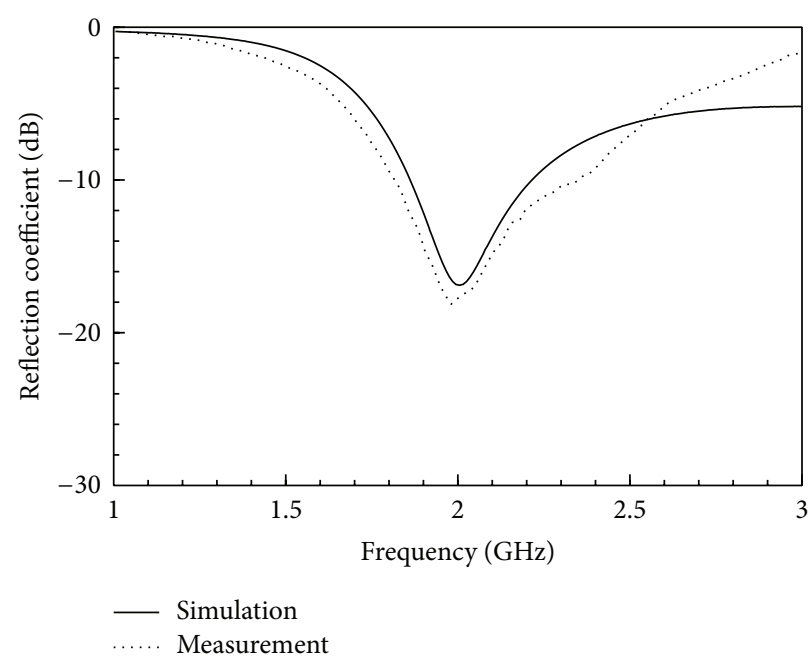

(a)

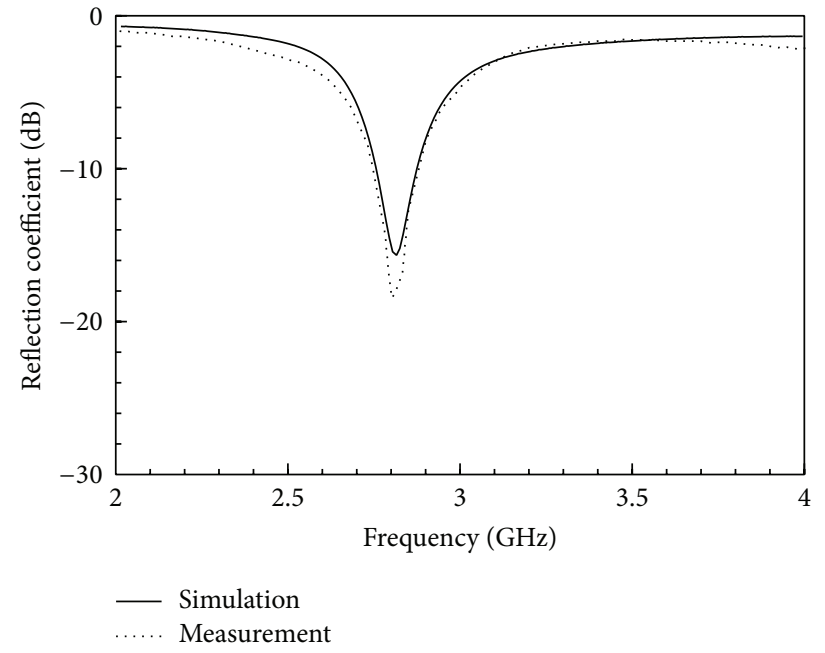

(b)

FIGURE 3: Simulated and measured reflection coefficients of the reference antennas; (a) the monopole antenna and (b) the slot antenna.

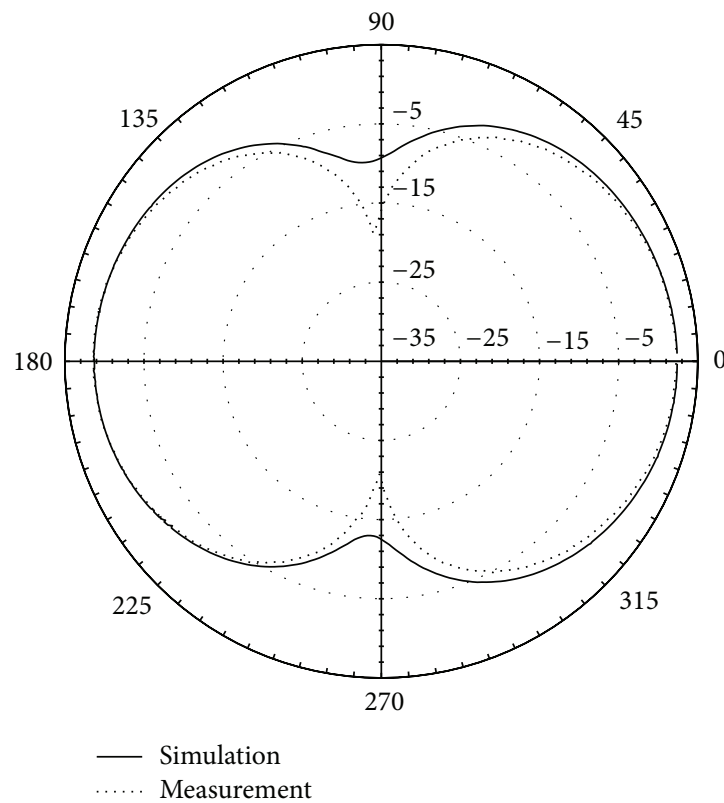

(a)

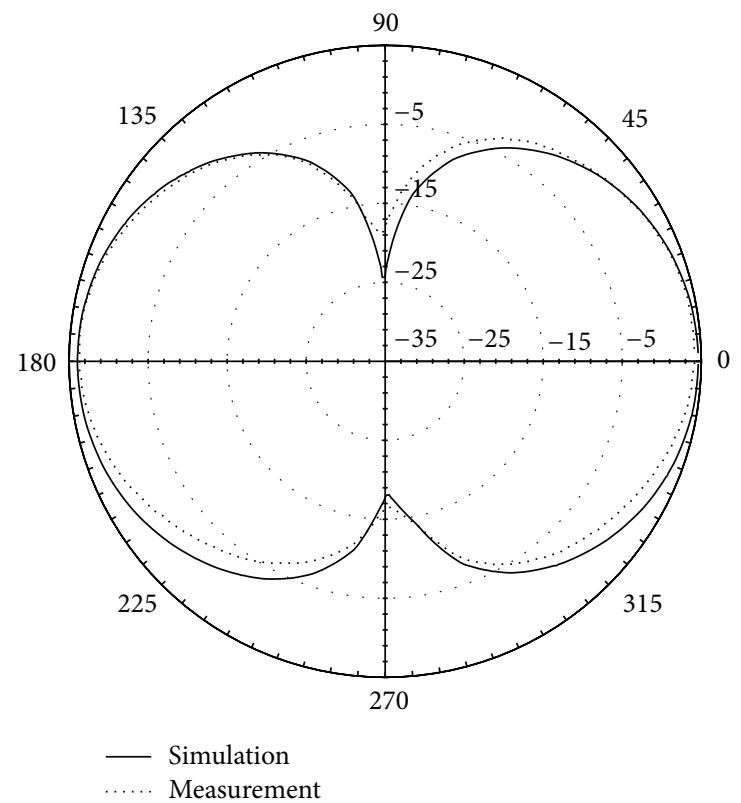

(b)

FIGURE 4: Simulated and measured radiation patterns of the reference antennas ( $x z$-plane); (a) the monopole antenna and (b) the slot antenna.

the same substrate (FR-4). The thickness of the substrates was $1 \mathrm{~mm}$. The geometries of the reconfigurable monopole and slot antennas are shown in Figures 5(a) and 5(b), respectively. For the monopole antenna, the size of the substrate was $30 \mathrm{~mm}\left(L_{\mathrm{mr}}\right) \times 60 \mathrm{~mm}\left(W_{\mathrm{mr}}\right)$, and the length of the ground plane was $30 \mathrm{~mm}\left(\mathrm{GL}_{r}\right)$. Top and bottom ground planes were connected via holes. A single RF switch $\left(\mathrm{SW}_{m}\right)$ was placed in series between two sections of the monopole radiator. When the $\mathrm{SW}_{m}$ was in the OFF-state, the length of the antenna was $6.9 \mathrm{~mm}$ (AL2), and the radiator operated at a high frequency, $5 \mathrm{GHz}$. On the other hand, when the RF switch was in the ON-state, the electrical length of the antenna was $20 \mathrm{~mm}$
(AL1), and the antenna operated at a low frequency, $2 \mathrm{GHz}$. For the slot antenna, the size of the substrate was $70 \mathrm{~mm}$ $\left(W_{\mathrm{sr}}\right) \times 70 \mathrm{~mm}\left(L_{\mathrm{sr}}\right)$, and the dimension of the slot was $47.5 \mathrm{~mm}(\mathrm{SL}) \times 2 \mathrm{~mm}(\mathrm{SW})$. The length of the coupled FL was $34.9 \mathrm{~mm}$, and the width of the feed line was $2 \mathrm{~mm}$ for a characteristic impedance of $50 \Omega$. Two RF switches $\left(\mathrm{SW}_{s} 1\right.$ and $\left.\mathrm{SW}_{s} 1\right)$ were placed in parallel between the slot in the bottom ground. When the two switches $\left(\mathrm{SW}_{s} 1\right.$ and $\left.\mathrm{SW}_{s} 1\right)$ were in the OFF-state, the electrical length of the slot was $47.5 \mathrm{~mm}$ (SL), and the corresponding resonance frequency of the antenna was $2 \mathrm{GHz}$. On the other hand, when the switches were in the ON-state, the electrical length of the slot (SL1) 

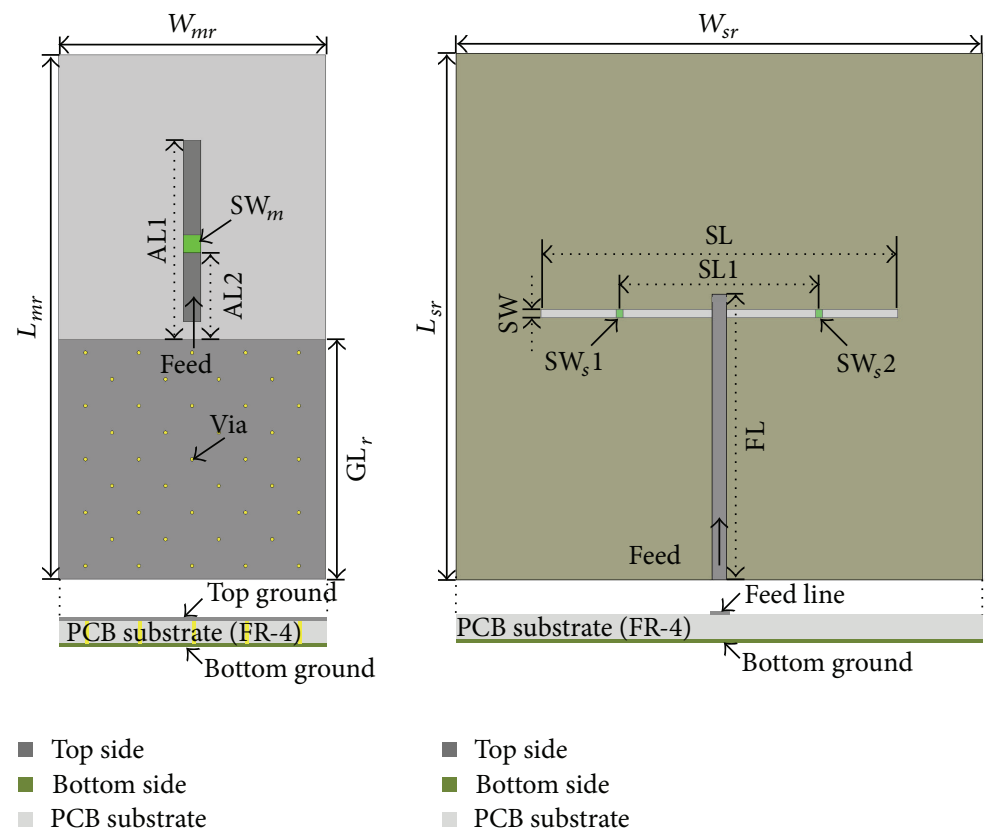

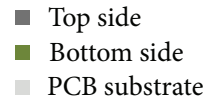

(a)

(b)

FIGURE 5: Geometry of the reconfigurable antennas with RF switches; (a) the monopole antenna (left) and (b) the slot antenna (right).

was $30.5 \mathrm{~mm}$, and the corresponding resonance frequency of the antenna was $2.8 \mathrm{GHz}$. Figure 6 shows the configurations of both reconfigurable monopole and slot antennas with the PIN diodes, including the biasing network. In this structure, the cathodes of the diodes are connected to the direction of the feeding input for the monopole and the ground for the slot. In addition, the anodes of the diodes are connected to the positive terminal of a DC battery in both antennas. In the forward bias of DC $1 \mathrm{~V}$, the current can pass through the diodes electrically in the so-called switch ON-state; in the reverse-bias of $\mathrm{DC} 0 \mathrm{~V}$, no current flows through the diodes; this is the so-called switch OFF-state. The top-side $\mathrm{PCB}$ of both antennas was configured by a feed line, and the bottom side of the PCB was composed of a switch bias circuit, including a DC battery to supply a DC-voltage, a dip switch to control the DC bias, and inductors to block the RF signal and noise. Inductors of $470 \mathrm{nH}$ were used for RF choking in both antennas. For the slot antenna, two capacitors of $10 \mathrm{pF}$ were used to improve the isolation characteristic between the $\mathrm{RF}$ and the DC signal. The DC was directly supplied to the radiator in the top side through a via-hole in the monopole antenna, and it was supplied to the slot in the bottom ground through a via-hole in the slot antenna.

The RF equivalent circuit of the PIN diode is shown in Figure 7. In the ON-state (forward bias), the PIN diode mainly behaves as a current-controlled resistor, which is expressed by a series resistor $\left(R_{s}\right)$ connected in series with a fixed inductor $(L)$. The series resistance can be inversely varied with the forward current over a range from a few tenths of Ohm to about $10 \mathrm{~K} \mathrm{Ohms.} \mathrm{Also,} \mathrm{in} \mathrm{the} \mathrm{OFF-state} \mathrm{(reverse}$ bias), the equivalent circuit consists of the shunt combination of the intrinsic-layer capacitance $\left(C_{R}\right)$ and the parallel

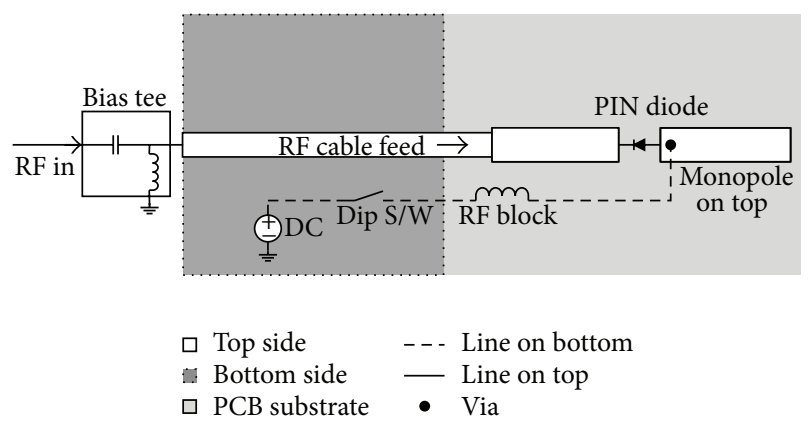

(a)

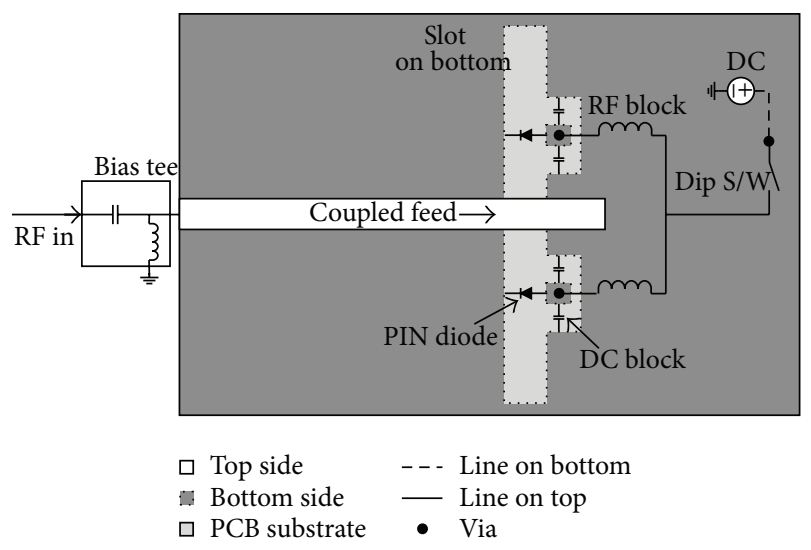

(b)

FIgURE 6: Configurations of the reconfigurable antenna with PIN diodes, including the biasing network; (a) the monopole antenna and (b) the slot antenna. 


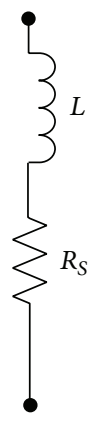

(a)

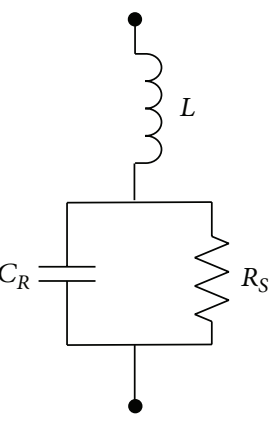

(b)
FIGURE 7: Equivalent circuit of a packaged PIN diode in its two-bias conditions; (a) ON-state (forward bias) and (b) OFF-state (reverse bias).

resistance $\left(R_{s}\right)$ in series with the fixed inductance $(L)$. The reactance and the resistance of the depleted intrinsic layer are represented by $C_{R}$ and $R_{s}$, respectively, and $C_{R}$ contains the stray capacitance due to the effects of the diode's package structure as well as those of the junction's capacitance. In this study, we used two types of diodes to check the performance differences by the diode type: MPP 4203 (Diode I) of Microsemi and BAR64 (Diode II) of Infineon technology. The PIN diodes used in the reconfigurable antennas were modeled as follows. First, the equivalent $R-L$ - $C$ circuit models for Diode I, including the parasitic packaging effects, were extracted from the PIN diode's datasheet. In the ON-state, the diode equivalent circuit was represented by a resistor, $R_{S}$ $(3 \Omega)$, with a fixed series inductor $L(0.2 \mathrm{nH})$, whereas in the OFF-state, the equivalent circuit was mainly represented by a capacitor, $C_{R}(0.1 \mathrm{pF})$, with a parallel resistor, $R_{S}(100 \mathrm{k} \Omega)$, and an inductor, $L(0.2 \mathrm{nH})$. In another model for Diode II, the equivalent circuit was represented by a resistor, $R_{S}$ $(2.1 \Omega)$, with a fixed series inductor, $L(0.6 \mathrm{nH})$, in the $O N$ state, whereas in the OFF-state, the circuit was represented by a capacitor, $C_{R}(0.17 \mathrm{pF})$, and a parallel resistor, $R_{S}(3 \mathrm{k} \Omega)$, with the inductor $L(0.6 \mathrm{nH})$. The photographs of the top and the bottom sides of the fabricated reconfigurable antennas with the PIN diodes are shown in Figure 8.

\subsection{Configuration of the Reconfigurable Antenna with RF-} MEMS Switch. We present two kinds of reconfigurable antennas with MEMS switches fabricated on the same substrate (FR-4; $\varepsilon_{r}=4.4, \tan \delta=0.02$ ) of $1 \mathrm{~mm}$ thickness, as shown in Figure 9. RMSW 201 of Radant Inc. was selected as the MEMS switch for the reconfigurable antennas. The switch has a volume of $1.9 \times 1.85 \times 0.6 \mathrm{~mm}^{3}$ [23]. For the installation, we glued the bottom of the switch with epoxy onto the antenna's substrate and baked it on a hot plate. Afterwards, it was wire-bonded to the antenna's lines and a biasing block. The MEMS switch has electrostatically actuated cantilever beams connected in a three-terminal configuration. Its functionality is analogous to that of an FET. Thus, the terminals are labeled as a source $(S)$, a drain $(D)$, and a gate $(G)$. In contrast to the PIN diode, the MEMS switch used mechanical movement to realize a short or an open circuit.
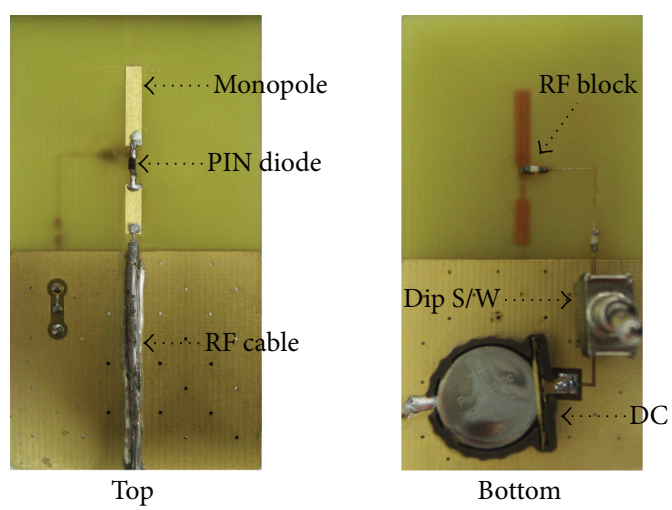

(a)
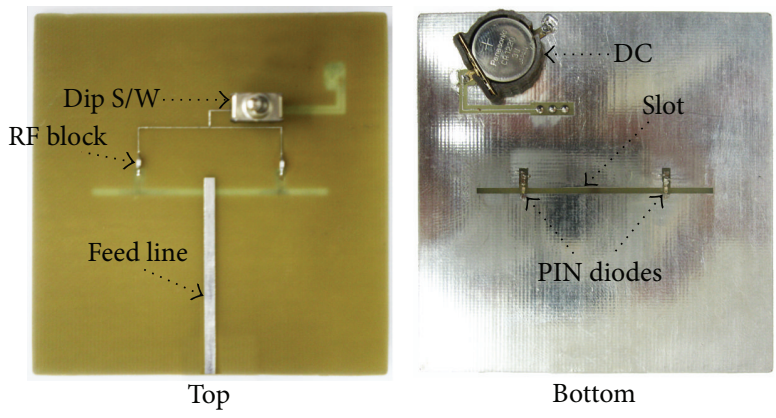

(b)

FIGURE 8: Photograph of the reconfigurable antennas with PIN diodes; (a) the monopole antenna and (b) the slot antenna.

By applying a high voltage between the two metal plates, one metal plate moved downward or upward to contact the other metalized terminals. In general, a high DC voltage (e.g., $100 \mathrm{~V}$ ) was required to control the mechanical switching with high switching reliability. The gate electrode of the MEMS switch was connected with gold $(\mathrm{Au})$ wire to the biasing circuit. The drain and the source bias pads were bonded on either side of the slot radiator. As shown in Figure 9(a), the switch was embedded between two microstrip monopole radiators in series. The switch operated in a similar manner to the PIN diode. When a bias voltage of $100 \mathrm{~V}$ was applied, the switch changed to the state of forward bias (ON-state). Thus, the radiator's length was electrically lengthened, and the antenna could operate in the low-frequency band of $2 \mathrm{GHz}$. In addition, we changed the MEMS switch to the reverse-biased (OFF-state) state by applying a $0 \mathrm{~V}$ high-frequency band operating at $5 \mathrm{GHz}$. The monopole antenna with the switch included a bias circuit for the switch control. The top side of the PCB was designed to include a radiator with an MEMS switch. The switch bias network included a DC battery, and the bottom side contained a DC-DC converter. The DC bias line had a resistor $(100 \mathrm{k} \Omega$ ) to control the operating current for the switch, and an inductor $(470 \mathrm{nH})$ was used for $\mathrm{RF}$ choking. The DC signal line was connected to the radiator through a hole in the structure of the reconfigurable slot antenna. When $0 \mathrm{~V}$ was applied to the two MEMS switches, the switch was in the reverse-biased state (OFF-state). In this condition, the electrical length of electrical length of the slot 


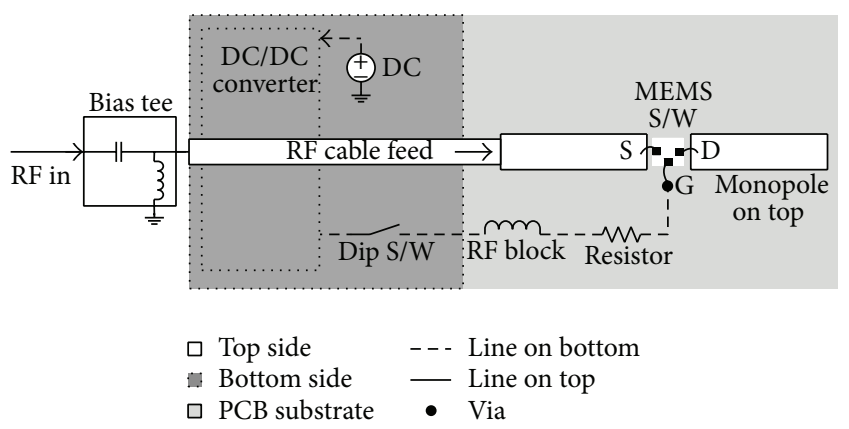

(a)

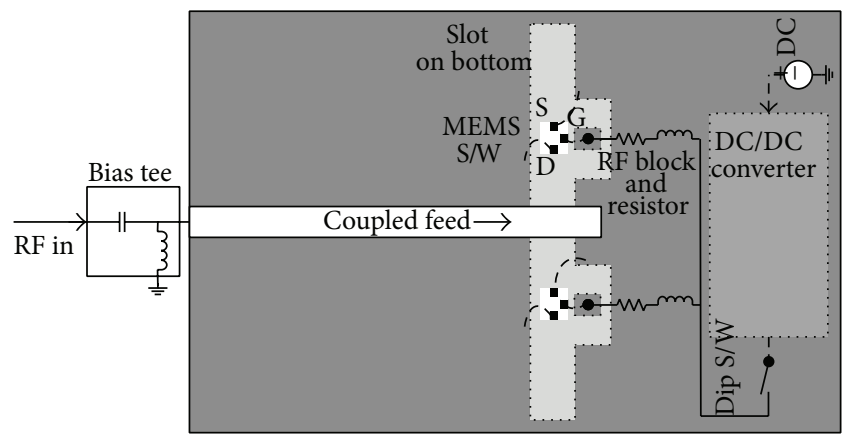

$\begin{array}{lll}\square & \text { Top side } \quad-- & \text { Line on bottom } \\ & \text { Bottom side } \quad-\text { Line on top }\end{array}$

$\square$ PCB substrate • Via

(b)

FIGURE 9: Configurations of reconfigurable antenna with RF-MEMS switches including the biasing network; (a) the monopole antenna and (b) the slot antenna.

was lengthened, and the antenna operated at $2 \mathrm{GHz}$. When we applied $100 \mathrm{~V}$, the slot radiator was electrically shortened for high-frequency band operation of $2.8 \mathrm{GHz}$ by the forwardbiased (ON-state) switch. The switch-bias network of the top side of the PCB was configured to include a coupled feed line, dip switch, an inductor, and a resistor. The bottom side of the PCB was composed of DC-DC converter circuitry, which included a battery. In the DC bias circuit, the resistor was $100 \mathrm{k} \Omega$, and the inductor was $470 \mathrm{nH}$. In addition, the shunt capacitor $(1 \mu \mathrm{F})$ was also used to protect the MEMS switch from a transient voltage.

The equivalent circuit of the MEMS switch is presented in Figure 10. Typically, when the switch was in the $O N$ state $(>90 \mathrm{~V})$, the resistance $\left(R_{S}\right)$ was $0.7 \Omega$, and the series inductance $\left(L_{S}\right)$ was $0.15 \mathrm{nH}$. When the switch was in the OFF-state ( $0 \mathrm{~V}$ or no bias), the inductance $\left(L_{S}\right)$ was $0.15 \mathrm{nH}$, and the series capacitance $\left(C_{\text {up }}\right)$ was $80 \mathrm{fF}$ in an up-state. The high-bias voltage $(100 \mathrm{~V})$ for the MEMS switch was provided by a DC-DC converter, which was designed mainly with a commercial voltage convertor, MAX5025 (Maxim Inc.), as shown in Figure 11, where $V_{c c}$ is the input supply voltage, FB is the feedback, SHDN is the shutdown voltage, and LX is the drain of the internal $40 \mathrm{~V} \mathrm{~N}$-channel DMOS [23]. In this circuit, D1 is a Schottky diode, (ZHCS500, of Zetex Inc.), and D2 D5 are silicon switching diodes (1N914 of Microsemi

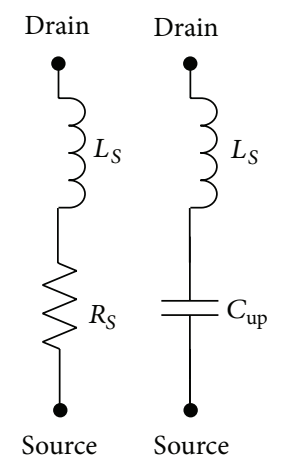

(a)

(b)

FIGURE 10: Equivalent circuit of a RF-MEMS switch in two-bias conditions; (a) the ON-state and (b) the OFF-state.

Inc.). C1-C5 are ceramic capacitors of $0.1 \mu \mathrm{F}$. Using (1), we can control the output voltage of the convertor [24]. The calculated resistance was $R_{1}=83 \mathrm{k} \Omega$ and $R_{2}=1 \mathrm{M} \Omega$ for a $100 \mathrm{~V}$ bias voltage for the MEMS switch. Figure 12 shows the photographs of the reconfigurable antenna with the MEMS switches:

$$
V_{\text {out }}=\frac{1.25\left(R_{1}+R_{2}\right)}{R_{2}}
$$

\subsection{Measurement Results of the Reconfigurable Antennas.} Figure 13 shows the measured reflection coefficients $\left(S_{11}\right)$ of the proposed reconfigurable monopole and slot antennas. Depending on the state of the RF switches, we measured the reflection coefficients of the reconfigurable antennas with two kinds of diodes (Diode I; MPP4203, Diode II; BAR64) and an MEMS switch (RMSW 201). Both reconfigurable monopole/slot antennas with these RF switches fully operated as frequency switching devices. Figures 13(a), 13(b), and 13(c) show the reflection coefficient of the reconfigurable monopole antenna with these RF switches. The measured values were below $-10 \mathrm{~dB}$ for both states at an operating frequency of $2 \mathrm{GHz}$ for the ON-state and $5 \mathrm{GHz}$ for the OFFstate. The bandwidths $\left(10>S_{11}[\mathrm{~dB}]\right)$ of the reconfigurable monopole antenna with both diodes were similar and more than $200 \mathrm{MHz}(10 \%)$ in the ON-state and $450 \mathrm{MHz}(9 \%)$ in the OFF-state. Also, the bandwidth of the reconfigurable monopole with the MEMS switch was similar to that of the antenna with the diodes. They were $170 \mathrm{MHz}(8.5 \%)$ in the ON-state and $540 \mathrm{MHz}(11 \%)$ in the OFF-state. In addition, the bandwidth of the reconfigurable monopole antenna in the ON-state was more than $150 \mathrm{MHz}$ narrower than that of the reference antenna, as mentioned in Section 2, owing to the use of the switches. Figures 13(d), 13(e), and 13(f) show the reflection coefficients of the reconfigurable slot antenna with RF switches. The measured values were below $-10 \mathrm{~dB}$ for both the ON- and the OFF-states at an operating frequency of $2.8 \mathrm{GHz}$ for the ON-state and $2 \mathrm{GHz}$ for the OFF-state. The bandwidths of the reconfigurable slot with both diodes were similar and more than $210 \mathrm{MHz}(7.5 \%)$ in the ON-state and $150 \mathrm{MHz}(7.5 \%)$ in the OFF-state. Also, the bandwidth of 


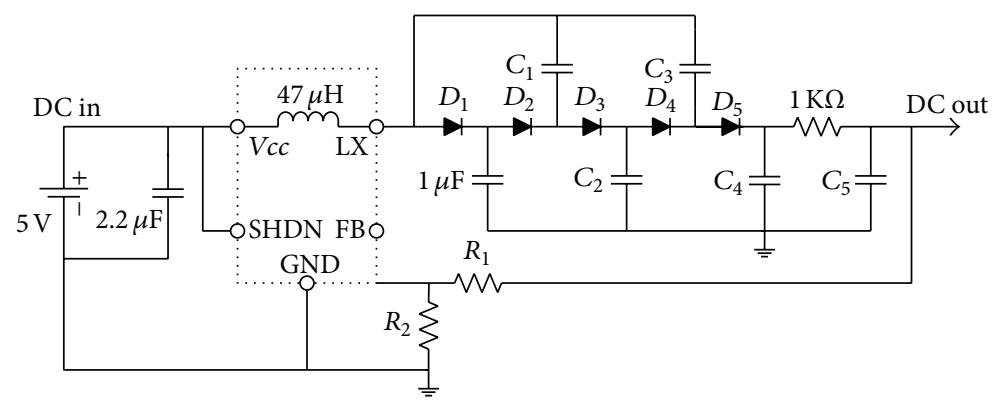

FIGURE 11: DC-DC converter circuit for the RF-MEMS switch.

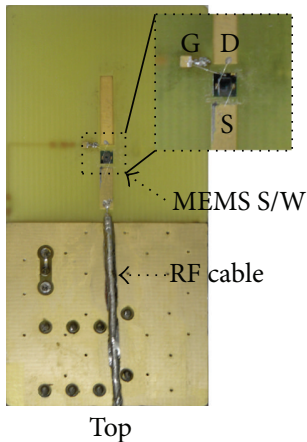

Top

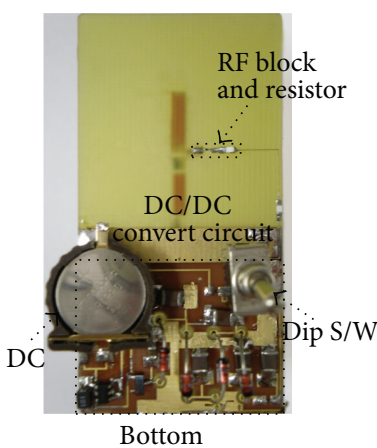

(a)
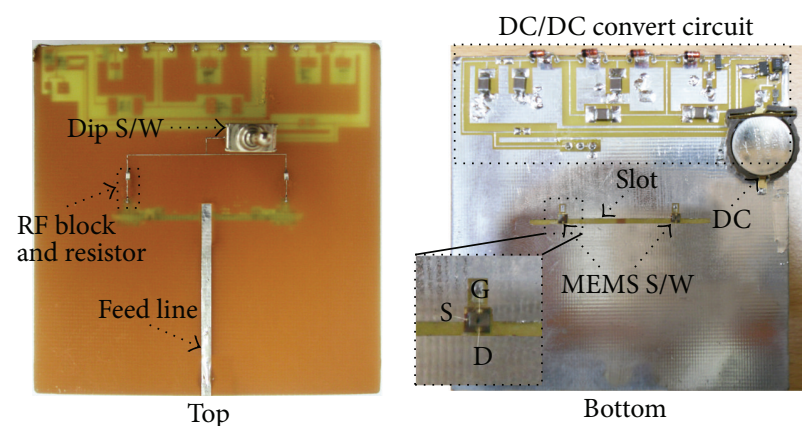

(b)

FIGURE 12: Photograph of the reconfigurable antennas with the MEMS switch; (a) the monopole antenna and (b) the slot antenna.

the reconfigurable slot with the MEMS switch was narrower than that of the diodes in the ON-state, $130 \mathrm{MHz}(4.6 \%)$, and was slightly wider than that of the diodes in the OFFstate, $180 \mathrm{MHz}$ (9\%). In addition, the bandwidth of the reconfigurable slot antenna with the diodes and the MEMS switch in the ON-state was more than $60 \mathrm{MHz}$ wider and $20 \mathrm{MHz}$ narrower, respectively, than that of the reference antenna, as mentioned in Section 2, owing to the RF switches' use. Figure 14 shows the radiation patterns in the $x z$-plane when the switch was in the ON-state in both reconfigurable monopole/slot antennas. Figure 14(a) shows the measured results at a low band of $2 \mathrm{GHz}$ for the reconfigurable monopole antenna, and Figure 14(b) shows the measured results at a high band of $2.8 \mathrm{GHz}$ for the reconfigurable slot antenna. The measurements of the peak gain and the radiation efficiency for the reference and the reconfigurable antennas are summarized in Table 1 . Both radiation patterns of the reconfigurable monopole/slot antennas were omnidirectional. The peak gains of the reconfigurable monopole antennas were $2.2 \mathrm{dBi}, 1.5 \mathrm{dBi}$, and $1.1 \mathrm{dBi}$ for the MEMS switch, Diode I, and Diode II, respectively. The peak gains of the reconfigurable slot antenna were $3.3 \mathrm{dBi}, 2.7 \mathrm{dBi}$, and $2.5 \mathrm{dBi}$ for the MEMS switch, Diode I, and Diode II, respectively. Meanwhile, the efficiencies of the reconfigurable monopole and slot antennas were $63 \sim 89 \%$ and $48 \sim 77 \%$, respectively. The peak gains of the reconfigurable antennas with the RF switches were lower than those of the reference antennas for both the monopole and the slot antenna, in the following order: MEMS $>$ Diode I $>$ Diode II. The order of the losses was MEMS switch $<$ Diode I $<$ Diode II. This will be discussed in Section 4 (the next section). The reconfigurable slot antennas had higher gain and lower efficiency than those of the reconfigurable monopole antennas because the radiation beam patterns of the slot antennas are more directive than those of the monopole antennas. Moreover, the gains and the efficiencies of the reconfigurable antennas were lower than those of the reference antenna owing to the latter's use of the RF switch.

\section{Performance Analysis of the Reconfigurable Antenna in the Far-Field Condition}

4.1. Measurement Setup. The RF performance of the reconfigurable antenna with the RF switches was investigated in relation to the radiating power and the linearity. Figure 15 shows the measurement setup for the radiating RF power of the reconfigurable antennas $(\mathrm{ON}$-state) in the far-field condition (2.5 meter). The reference antenna was located at the RX part (receiver), and the reconfigurable antenna was located at the TX part (transmitter). Figure 16 shows the measurement setup of the TX part. In this region, the RF signal was produced using a signal generator (N9310A, Agilent). The generated ON-state frequencies of both the reconfigurable monopole and slot antennas were 2.0 and $2.8 \mathrm{GHz}$, respectively. A power amplifier with a maximum available output power of $40 \mathrm{dBm}$ was used to amplify the signal from the generator because more than $24 \mathrm{dBm}$ (power class 3) or $27 \mathrm{dBm}$ (typical cellular phone transmission power: power class 2) of TX power was required, supposing 
TABLE 1: Comparison of the measured efficiency and peak gain of the reconfigurable antennas.

\begin{tabular}{lccccccccc}
\hline \multirow{2}{*}{ Quantity } & \multirow{2}{*}{ Unit } & & \multicolumn{2}{c}{ Monopole antenna } & \multicolumn{3}{c}{ Slot antenna } \\
& & Reference & MEMS & Diode I & Diode II & Reference & MEMS & Diode I & Diode II \\
\hline Peak antenna's gain & $\mathrm{dBi}$ & 2.4 & 2.2 & 1.5 & 1.1 & 4.7 & 3.3 & 2.7 & 2.5 \\
Antenna's efficiency & $\%$ & 97.3 & 88.7 & 70.3 & 62.5 & 90.2 & 76.5 & 46.1 & 47.5 \\
\hline
\end{tabular}

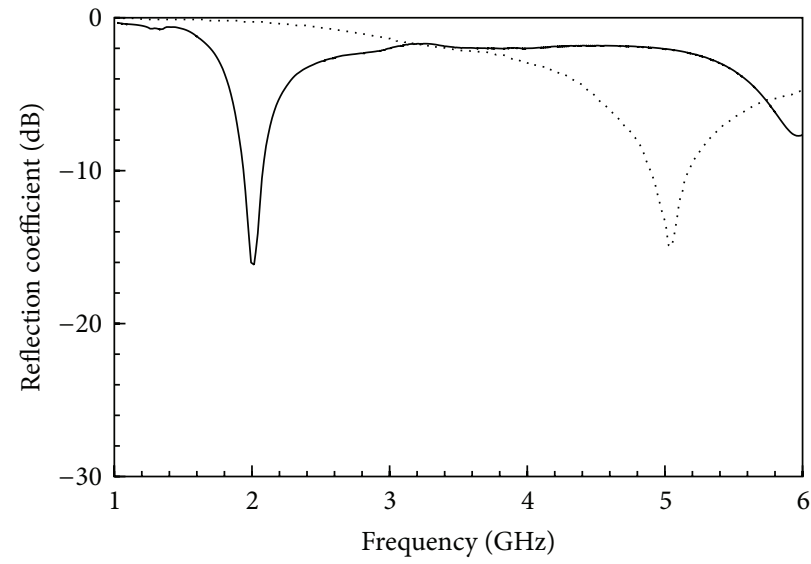

(a)

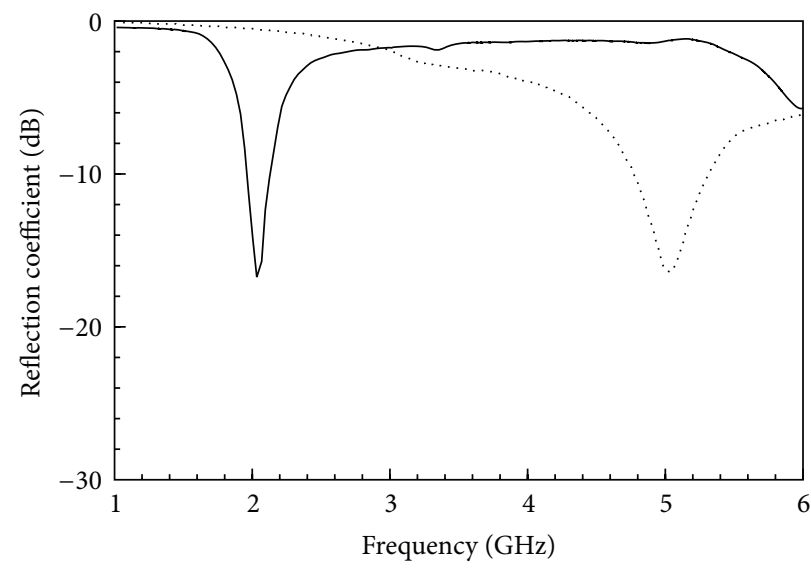

(c)

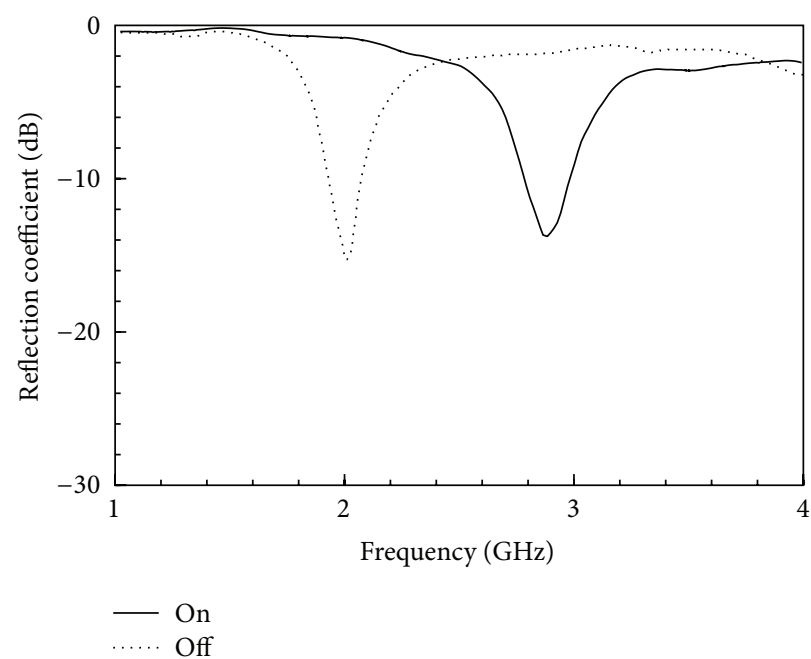

(e)

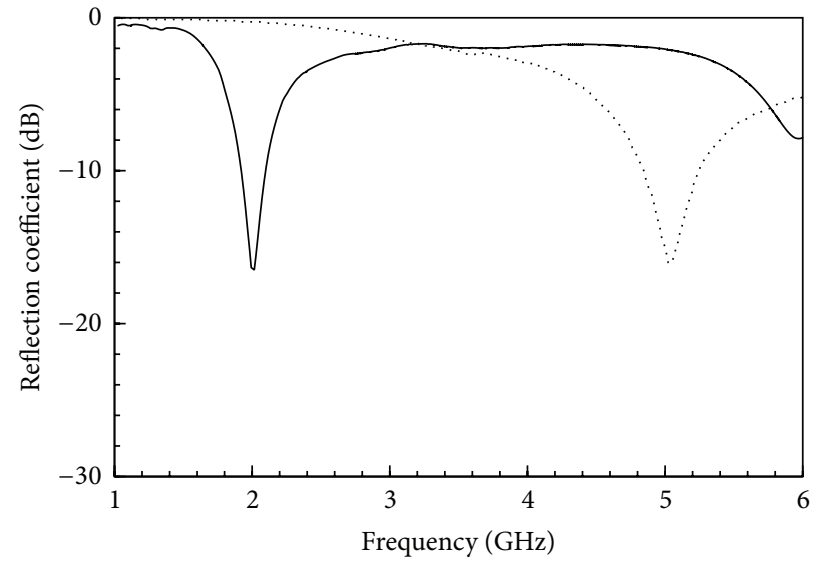

(b)

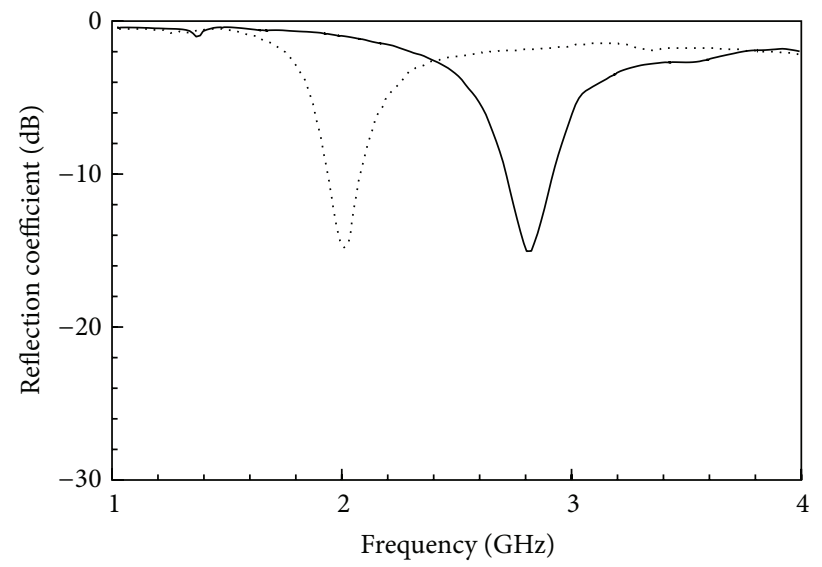

(d)

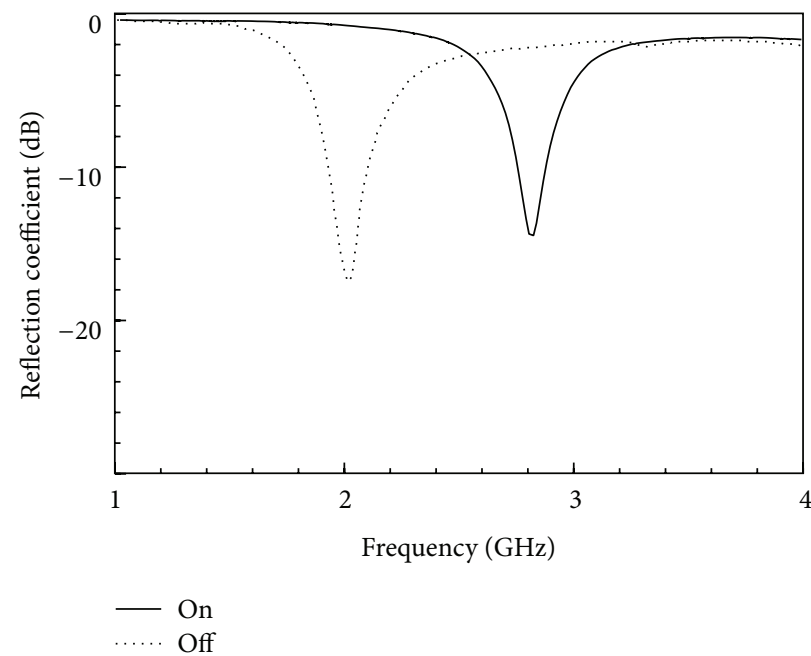

(f)

FIGURE 13: Measured reflection coefficients $\left(\left|S_{11}\right|\right)$ of the proposed reconfigurable antennas; (a) the monopole with Diode I, (b) the monopole with Diode II, (c) the monopole with MEMS switch, (d) the slot with Diode I, (e) the slot with Diode II, and (f) the slot with MEMS switch. 

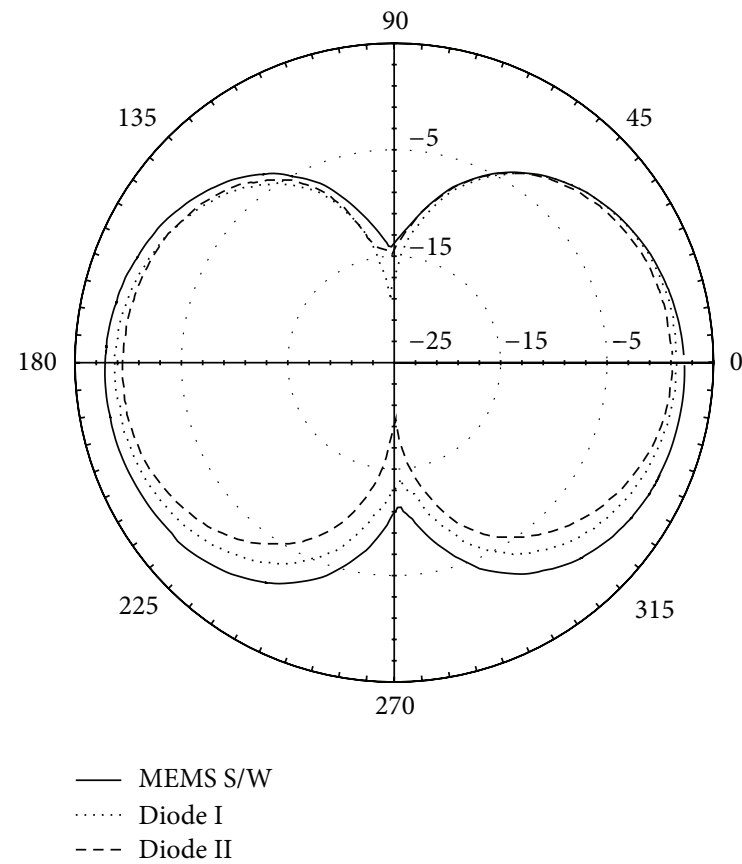

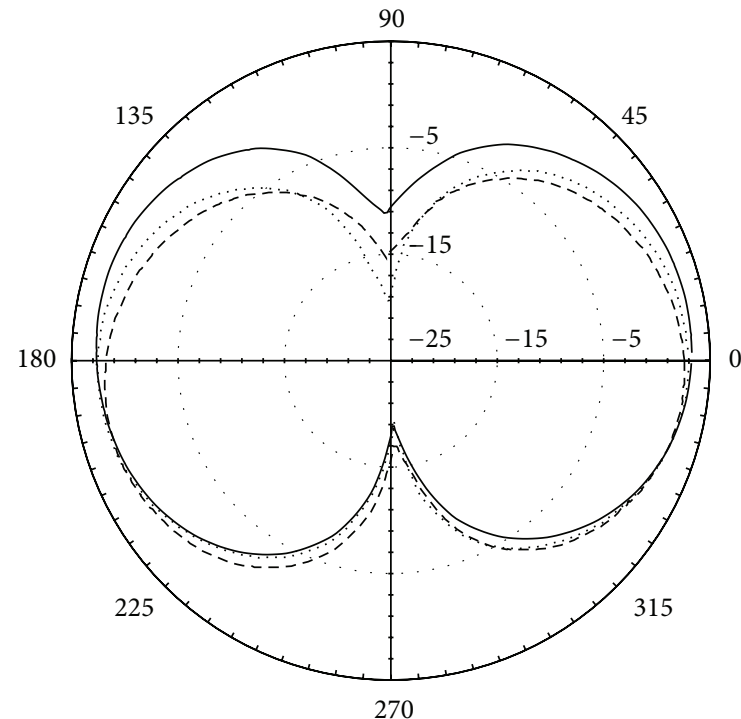

$\begin{array}{ll}\text { —... } & \text { MEMS S/W } \\ \ldots-- & \text { Diode I } \\ -- & \text { Diode II }\end{array}$

(a)

(b)

FIGURE 14: The radiation pattern of the proposed reconfigurable antennas ( $x z$-plane); (a) the monopole antenna and (b) the slot antenna.

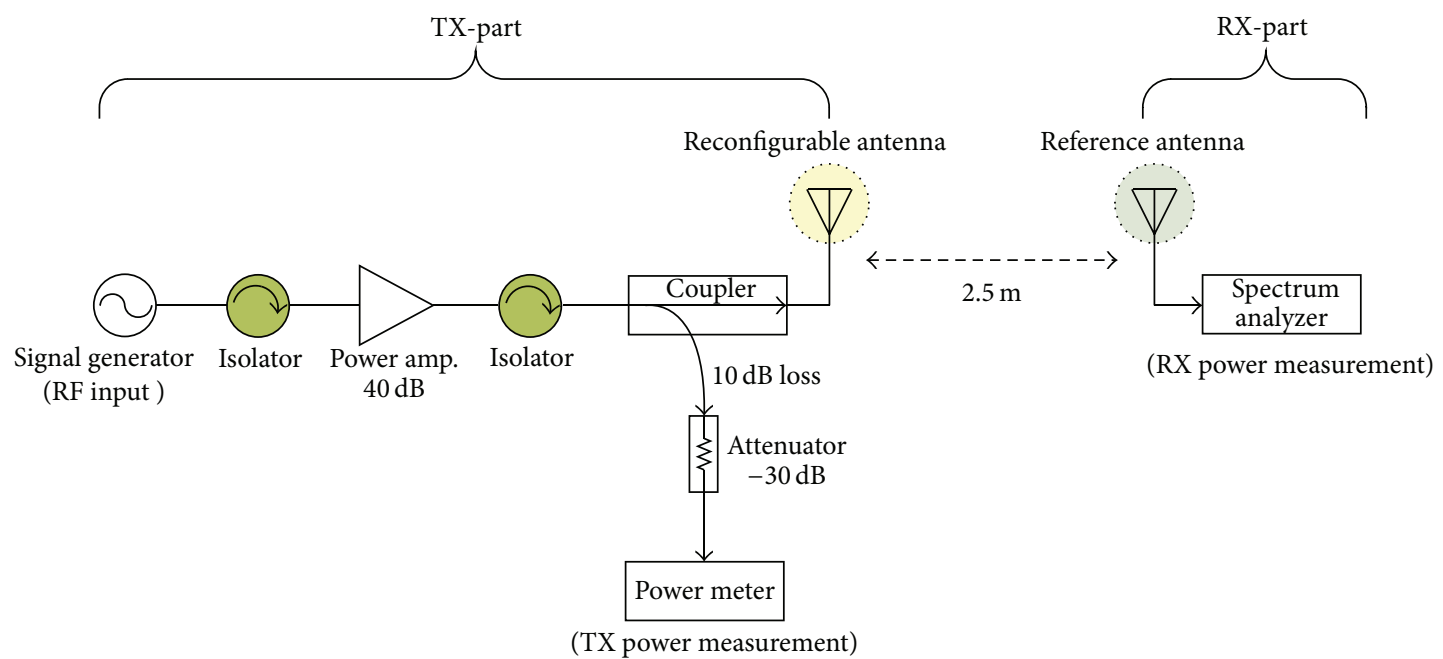

FIGURE 15: Block diagram of RF power measurement in the far-field condition.

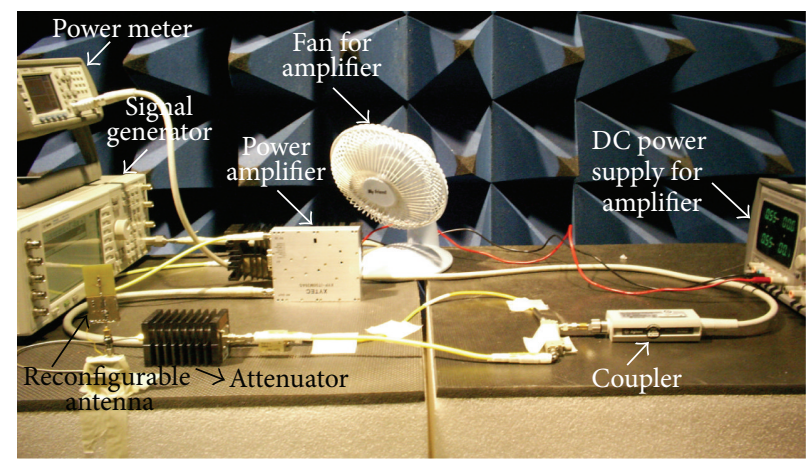

FIGURE 16: Photograph of the RF-power measurement (TX-part). 


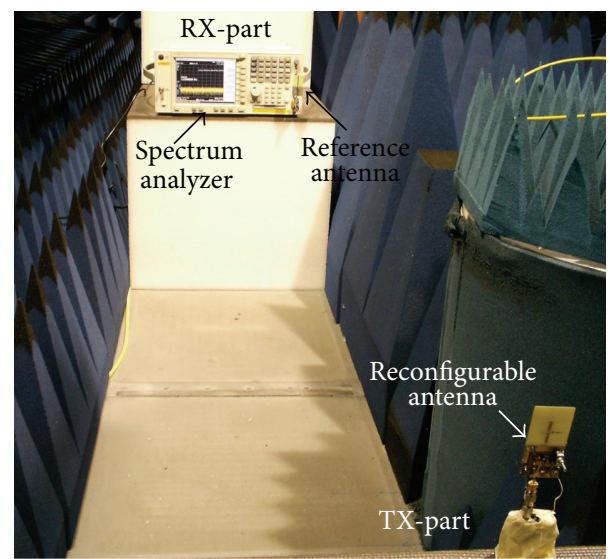

FIGURE 17: Photograph of the RF-power measurement in the farfield condition.

that there is a maximum TX power of a typical small mobile $[25,26]$. Even more power, up to $35 \mathrm{dBm}$, was required for the linearity check of RF switches in the reconfigurable antenna. A coupler and a power meter (N1911A, Agilent) were used to measure the input power in the reconfigurable antenna. In addition, two isolators were used to enhance the matching condition among the components and to protect the components from the reflected signal power. Finally, the RX power through the reference antenna was read with a spectrum analyzer. Figure 17 shows the real test setup in the anechoic chamber of Orbit-FR Inc. All the tests were performed in the far-field condition of $2.5 \mathrm{~m}$, and the test components were installed on the chamber ground and placed behind the antennas so as not to affect the test results by signal scattering.

4.2. Linearity and Power Handling Capability of the Diodes. In diodes in the reconfigurable antennas of mobile phones or other wireless terminals, linearity and power handling capability are important issues. In general, as the transmitting power increases, the measured output power should also linearly increase proportionally to the input power. However, nonlinear characteristics of diodes cause highorder intermodulation distortion, which results in a deviation from the linear relationship of the input and the output power. The average output power of the mobile terminal for 2nd generation CDMA and 3rd generation WCDMA for multimedia communication services is about $10 \mathrm{dBm}$ in suburban areas and $5 \mathrm{dBm}$ in urban areas. The maximum output power is $24 \mathrm{dBm}$ (power class 3) or $27 \mathrm{dBm}$ (typical cellular phone transmission power: power class 2) for WCDMA terminals and $3 \mathrm{G}$ mobile phones $[25,26]$. Thus, it is important to evaluate the power rating and the linearity of the switching devices used in the reconfigurable antenna for the typical operation of the terminals. In this aspect, we investigated the maximum available power and the linearity of the switching components. The Diodes I and II were embedded in a microstrip line in series, and we measured the output power using the spectrum analyzer by increasing the input power from $0 \mathrm{dBm}$ to $35 \mathrm{dBm}$. The photograph of

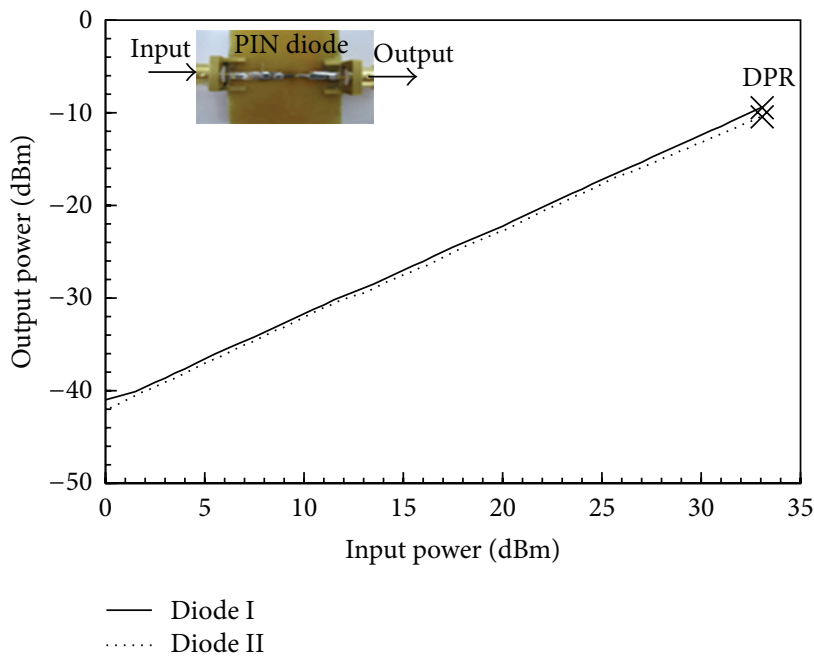

FIGURE 18: Comparison of the linearity of the PIN diodes (Diode I, Diode II).

the fabricated circuit and the test results of the diodes are shown in Figure 18. The results confirmed that the power rating (DPR) of both diodes is about $32 \mathrm{dBm}$ and that the linearity of both diodes is also preserved up to the power rating $(32 \mathrm{dBm})$. The findings confirm that the diodes are appropriate for commercial mobile devices within $24 \mathrm{dBm}$, which is the maximum power $(24 \mathrm{dBm})$ of a mobile in terms of linearity and power-handling capability. We did not assess the power of the MEMS switch because the MEMS switch generally can be operated stably above $33 \mathrm{dBm}$ [25].

\subsection{Receiving Power and Linearity of the Reconfigurable} Antennas. We experimentally analyzed the performance of the reconfigurable antennas as well as that of the reference antennas, to compare the receiving power and the linearity of the reconfigurable antenna using RF switches in the farfield condition. In this test, we increased the input power of the antenna (reference and reconfigurable) in the TX part using a signal generator from $0 \mathrm{dBm}$ to $35 \mathrm{dBm}$, and we measured the receiving power through the reference antenna of the RX part using the spectrum analyzer. Figures 19 and 20 show the plot of the measured receiving power level of the monopole antenna (ON-state, $2 \mathrm{GHz})$ and the slot antenna $(\mathrm{ON}$-state, at $2.8 \mathrm{GHz})$. Table 2 provides a summary of the calculations and measurements of the receiving power. To compare the calculated and the measured receiving power, we used Friis's formula in (2), which gave the power received by one under idealized conditions given that another antenna some distance away is transmitting a known amount of power:

$$
\frac{P_{r}}{P_{t}}=G_{t} G_{r}\left(\frac{\lambda}{4 \pi R}\right)^{2},
$$

where $P_{r}$ is the power received by the RX antenna, $P_{t}$ is the transmitting power of the TX antenna, $G_{t}$ and $G_{r}$ are the antenna gains of the transmitting and the receiving antennas, respectively, $\lambda$ is the wavelength, and $R$ is the distance 
TABLE 2: Comparison of the calculated and the measured receiving power.

\begin{tabular}{lccccccccc}
\hline \multirow{2}{*}{ Quantity } & \multirow{2}{*}{ Unit } & \multicolumn{3}{c}{ Monopole antenna } & \multicolumn{3}{c}{ Slot antenna } \\
& & Reference & MEMS & Diode I & Diode II & Reference & MEMS & Diode I & Diode II \\
\hline Calculated RX power & $\mathrm{dBm}$ & -34.5 & -34.7 & -35.4 & -35.8 & -29.9 & -31.3 & -31.7 & -32.1 \\
Measured RX power & $\mathrm{dBm}$ & -35.2 & -35.6 & -36.8 & -37.5 & -30.3 & -32.1 & -33.0 & -33.3 \\
Difference & $\mathrm{dB}$ & 0.7 & 0.9 & 1.4 & 1.7 & 0.4 & 0.8 & 1.3 & 1.2 \\
\hline
\end{tabular}

${ }^{*}$ The calculations were performed at the TX power condition of $10 \mathrm{dBm}$.

between the RX and the TX antennas. The calculated and the measured receiving power from the sample monopole and slot antennas at a transmitting power of $10 \mathrm{dBm}$ are summarized in Table 2. The calculated and the measured RX power levels were similar, and differences were increased in the lower RX power level with Diodes I and II for both monopole and slot antennas. The measured receiving power level of both the monopole antenna and the slot antenna increased linearly. The measured receiving power of the reference monopole antenna was $0.4 \mathrm{~dB}$ higher than that of the reconfigurable antennas with the MEMS switches and 1.6 2.3 $\mathrm{dB}$ higher than that of the reconfigurable antennas with the PIN diodes (Diode I \& II) as shown in Figure 19 and Table 2. The order of the receiving power level was Reference $>$ MEMS $>$ Diode I $>$ Diode II. Therefore, we can assume that the RX power loss of the reconfigurable monopole antenna with the MEMS switch is $0.4 \mathrm{~dB}$ and that of the diodes is $1.6 \sim 2.3 \mathrm{~dB}$. The PIN diodes (Diode I \& II) were destroyed by an input power of $32 \mathrm{dBm}$ (DPR), which is the same value in the PIN diode test of Figure 18. Thus, the reconfigurable antennas with PIN diodes do not operate over that input power $(32 \mathrm{dBm})$. The reconfigurable antenna with the direct-feed structure (monopole, etc.) has a power rating by series connection with the RF switches, and the linearity was maintained upon that power rating (DPR). In addition, the measured receiving power of the reference slot antenna was $1.8 \mathrm{~dB}$ higher than that of the reconfigurable antennas with the MEMS switches, and 2.7 3 dB higher than that of the reconfigurable antennas with PIN diodes (Diode I \& II) as shown in Figure 20 and Table 2. The order of the receiving power level was the same as with the previous monopole antenna test: Reference > MEMS > Diode I > Diode II. Therefore, we can assume that the RX power loss of the reconfigurable slot antenna with the MEMS switch is $1.8 \mathrm{~dB}$ and that of the diodes is $2.7 \sim 3 \mathrm{~dB}$. Here, the reconfigurable slot antennas with the PIN diodes operated up to $35 \mathrm{dBm}$ with normal diode operation. In the monopole structure using direct feeding, the switches were installed in the monopole radiator in series, and the antenna's input power directly passed through the switches in the ON-state. Thus, the switch operation can be limited by the input power level. In contrast, the switches in the slot structure using indirect feeding were mounted in the slot; in this case, regardless of the $\mathrm{ON}$ - and the OFF-state, the switches have no relation with the input power because the antenna's input power does not pass through the switches.

Therefore, this experiment confirmed that the maximum power rating of the reconfigurable antenna can be determined by the antenna's feeding method (direct/indirect feed)

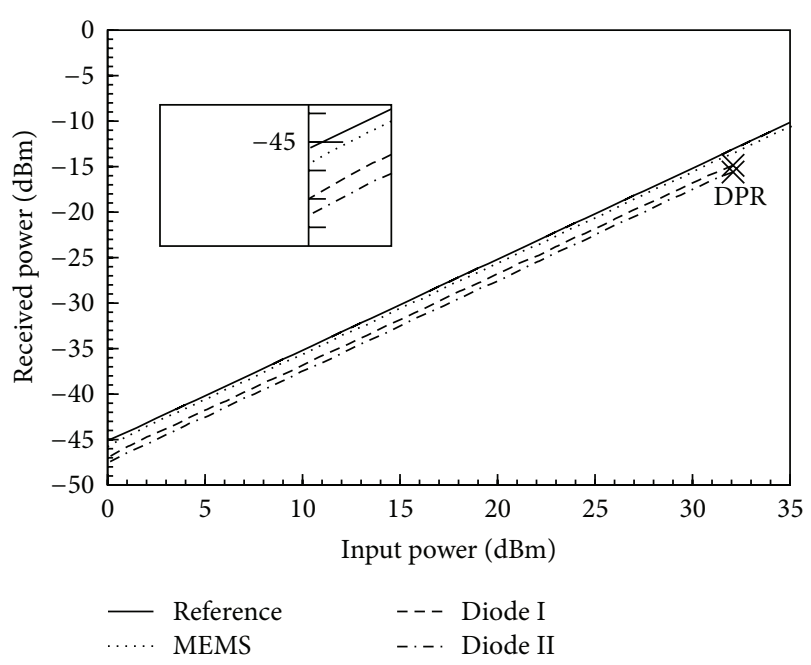

FIGURE 19: Comparison of the received power for the reconfigurable monopole antenna with RF switches in the far-field condition.

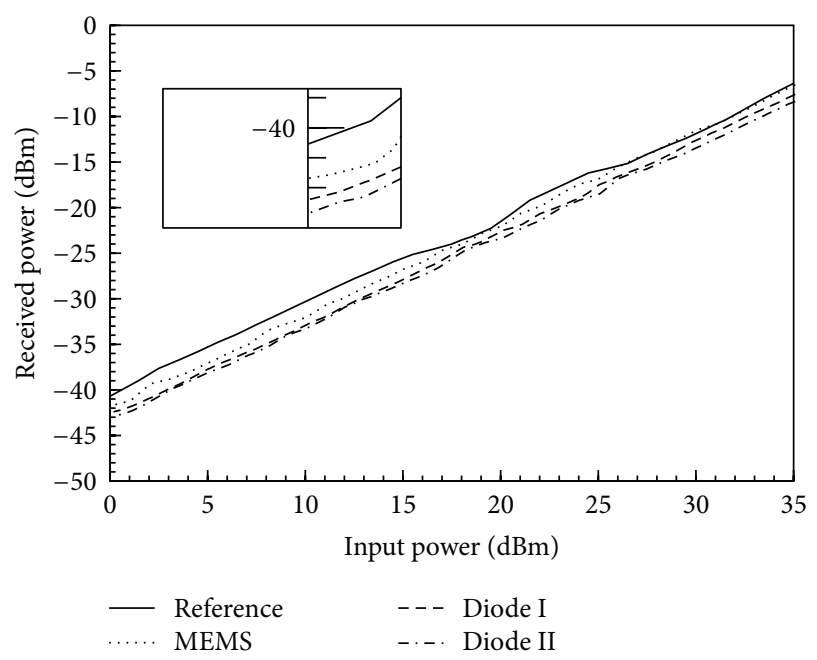

FIGURE 20: Comparison of the received power for the reconfigurable slot antenna with the RF switches in the far-field condition.

and the maximum power rating of the RF switches. The operational tests of both the reconfigurable monopole and slot antennas verified that the reconfigurable antenna with general RF switches could be operated above $24 \mathrm{dBm}$ (power class 3) or $27 \mathrm{dBm}$ (typical cellular phone transmission power: power class 2 ). This is the maximum operating power 
$J_{\text {surf }}(\mathrm{A} / \mathrm{m})$
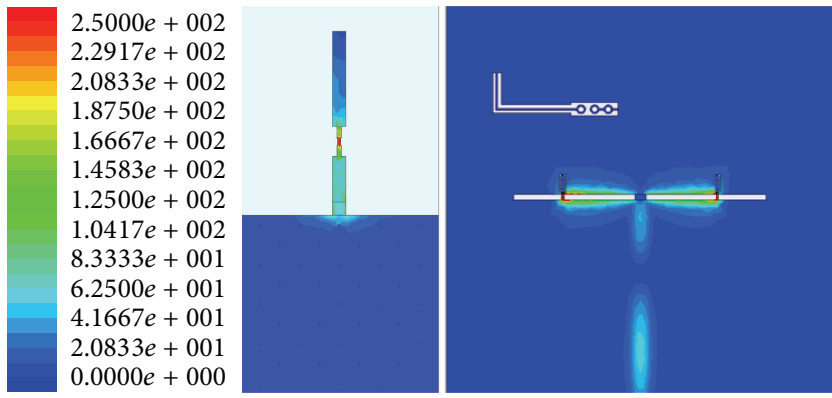

(a)
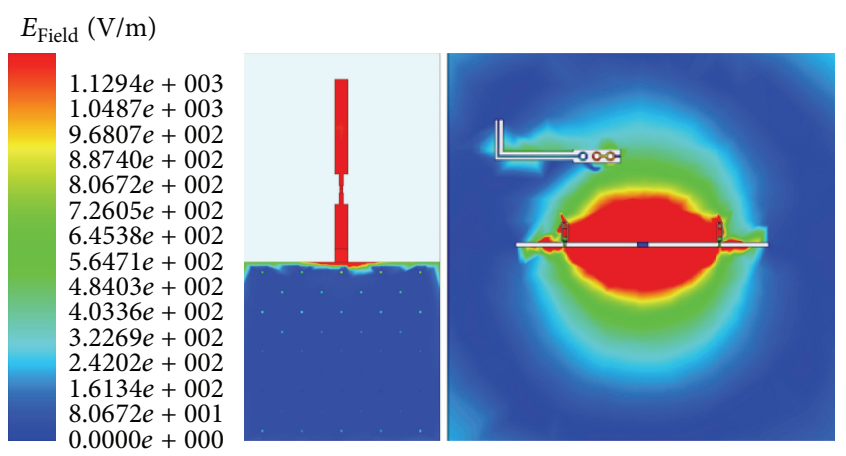

(b)

FIGURE 21: Field distribution on the reconfigurable antennas with Diode I; (a) the surface current density $(J[\mathrm{~A} / \mathrm{m}])$ and (b) the surface electric field intensity $(E[\mathrm{~V} / \mathrm{m}])$.

of mobile terminals because the power rating is more than that value, and the commonly used RF switches such as PIN and MEMS operate linearly up to that input power level.

The field distributions on the reconfigurable antenna with Diode I are shown in Figure 21. Figure 21(a) shows the surface current density in cases where the switch is in the ON-state. The maximum surface current density was $420(\mathrm{~A} / \mathrm{m})$ for the diode of the slot antenna and $250(\mathrm{~A} / \mathrm{m})$ for the monopole antenna. The surface electric field intensity is shown in Figure 21(b). The electric field intensity was $1,200(\mathrm{~V} / \mathrm{m})$ for the diode of the slot antenna and 5,000 $(\mathrm{V} / \mathrm{m})$ for the monopole antenna. The monopole antenna representing the direct-feed type had higher electric field intensity on the diode than that of the slot antenna with the coupled-feed type. The power through the diode was $0.5 \mathrm{~W}$ for the slot antenna and $1.25 \mathrm{~W}$ for the monopole antenna. Therefore, the directly exited RF power to the RF switch of the direct-fed antenna was higher $(0.75 \mathrm{~W})$ than that of the coupled-type antenna. All the results in Figure 21 were simulated using the commercial electromagnetic simulation HFSS of Ansoft Inc. Although the diode switches exhibit a higher loss and a lower power rating compared with mechanical switches such as the MEMS switches; however, diodes are widely used in many applications due to their comparable performance in terms of linearity and power rating and their low cost. Diode switches are also beneficial for use in simple biasing circuits.

\section{Conclusion}

In this paper, we analyzed the RF performances of reconfigurable antennas with respect to the linearity and the receiving power. We simulated and measured monopole (direct feed) and slot (indirect feed) antennas employing RF switches (an RF MEMS switch and two PIN diodes). We designed a biasing circuit, which we embedded in each antenna, and simulated the performance of the antenna. We measured the reconfigurable antenna in the far-field condition in an anechoic chamber. The receiving power level difference between the reference antenna and the reconfigurable antenna was $0.5 \sim$ $3 \mathrm{~dB}$; the order of the receiving power level was Reference > MEMS > Diode I > Diode II because the RX power loss of the reconfigurable antenna was reversed in the order of Diode II $>$ Diode I > MEMS > Reference. The measured receiving power level of the reconfigurable antennas linearly increased up to the maximum power rating of the reconfigurable antenna. Also, we confirmed that the maximum power rating of the reconfigurable antenna is $33 \mathrm{dBm}$ for monopole (direct feed), and this can be determined by the antenna's feeding method (direct/indirect feed). In addition, we experimentally verified that the reconfigurable antenna with general RF switches could be operated above $24 \mathrm{dBm}$ (power class 3 ) or $27 \mathrm{dBm}$ (typical cellular phone transmission power: power class 2), which is the maximum operating power of mobile terminals, and that they operate linearly up to that input power level. Thus, we confirmed that the reconfigurable antennas with the RF switches can be applied in mobile terminals to provide multiple services due to their less operation power than the rating and conserving linearity up to the max power. Although we found that the RF-MEMS switch is an appropriate device for reconfigurable antennas, it would be worthwhile to address issues related to cost, reliability, and the complexity of the biasing scheme, and so forth. Bearing these in mind, we can consider that the diodes are more appropriate devices than the MEMS switches, especially for mobile phones. To date, this study is the first to attempt to explore the RF characteristics of reconfigurable antennas. The scientific approach and design examples used in this paper are expected to be widely employed for reconfigurable antenna designs.

\section{Conflict of Interests}

The authors declare that there is no conflict of interests regarding the publication of this paper.

\section{Acknowledgments}

The authors are grateful to the Microwave Device Lab at Seoul National University of Science and Technology, especially, Kim Jae Young at MDL, and S. G. Kang at microsystems packaging. This work was supported by a National Research Foundation (NRF) of Korea Grant funded by the Korea government (no. 2013R1A2A2A01068058). 


\section{References}

[1] C. W. Jung, I. Kim, Y. Kim, and Y. E. Kim, "Multiband and multifeed antenna for concurrent operation mode," IET Electronics Letters, vol. 43, no. 11, pp. 600-602, 2007.

[2] I. Yeum, J. Park, J. Kim, J. Wee, B. Kim, and C. Jung, "Compact and contact quad-band (DVB-H UHF/L, WLAN $11 \mathrm{a} / \mathrm{b}$ ) antenna for PMP applications," IET Electronics Letters, vol. 46, no. 1, pp. 11-13, 2010.

[3] C. Yang, H. Kim, and C. Jung, "Compact broad dual-band antenna using inverted-L and loop for DVB-H applications," IET Electronics Letters, vol. 46, no. 21, pp. 1418-1419, 2010.

[4] I. Kim, C. W. Jung, Y. Kim, and Y. E. Kim, "Low-profile wideband mimo antenna with suppressing mutual coupling between two antennas," Wiley Wiley Microwave and Optical Technology Letters, vol. 50, no. 5, pp. 1336-1339, 2008.

[5] D. Peroulis, K. Sarabandi, and L. P. B. Katehi, "Design of reconfigurable slot antennas," IEEE Transactions on Antennas and Propagation, vol. 53, no. 2, pp. 645-654, 2005.

[6] C. W. Jung, Y. J. Kim, Y. E. Kim, and F. de Flaviis, "Macromicro frequency tuning antenna for reconfigurable wireless communication systems," IET Electronics Letters, vol. 43, no. 4, pp. 201-202, 2007.

[7] Z. Liu, K. Boyle, J. Krogerus et al., "MEMS-switched, frequencytunable hybrid slot/PIFA antenna," IEEE Antennas and Wireless Propagation Letters, vol. 8, pp. 311-314, 2009.

[8] P. Panaïa, C. Luxey, G. Jacquemod, R. Staraj, L. Petit, and L. Dussopt, "Multistandard reconfigurable PIFA antenna," Wiley Microwave and Optical Technology Letters, vol. 48, no. 10, pp. 1975-1977, 2006.

[9] A. C. K. Mak, C. R. Rowell, R. D. Murch, and C. L. Mak, "Reconfigurable multiband antenna designs for wireless communication devices," IEEE Transactions on Antennas and Propagation, vol. 55, no. 7, pp. 1919-1928, 2007.

[10] B. A. Cetiner, G. Roqueta Crusats, L. Jofre, and N. Biyikli, "RF MEMS integrated frequency reconfigurable annular slot antenna," IEEE Transactions on Antennas and Propagation, vol. 58, no. 3, pp. 626-632, 2010.

[11] S. Nikolaou, N. D. Kingsley, G. E. Ponchak, J. Papapolymerou, and M. M. Tentzeris, "UWB elliptical monopoles with a reconfigurable band notch using MEMS switches actuated without bias lines," IEEE Transactions on Antennas and Propagation, vol. 57, no. 8, pp. 2242-2251, 2009.

[12] N. Kingsley, D. E. Anagnostou, M. M. Tentzeris, and J. Papapolymerou, "RF MEMS sequentially reconfigurable sierpinski antenna on a flexible organic substrate with novel DC-biasing technique," Journal of Microelectromechanical Systems, vol. 16, no. 5, pp. 1185-1192, 2007.

[13] G. H. Huff, J. Feng, S. Zhang, and J. T. Bernhard, "A novel radiation pattern and frequency reconfigurable single turn square spiral microstrip antenna," IEEE Microwave and Wireless Components Letters, vol. 13, no. 2, pp. 57-59, 2003.

[14] S. J. Ha, C. W. Jung, and Y. Kim, "Reconfigurable 3D beam steering for intelligent antenna system," Wiley Microwave and Optical Technology Letters, vol. 53, no. 11, pp. 2615-2619, 2011.

[15] C. won Jung, M. J. Lee, G. P. Li, and F. de Flaviis, "Reconfigurable scan-beam single-arm spiral antenna integrated with RFMEMS switches," IEEE Transactions on Antennas and Propagation, vol. 54, no. 2, pp. 455-463, 2006.

[16] G. H. Huff and J. T. Bernhard, "Integration of packaged RF MEMS switches with radiation pattern reconfigurable square spiral microstrip antennas," IEEE Transactions on Antennas and Propagation, vol. 54, no. 2, pp. 464-469, 2006.

[17] A. Grau, J. Romeu, M. J. Lee, S. Blanch, L. Jofre, and F. de Flaviis, "A dual-linearly-polarized MEMS-reconfigurable antenna for narrowband MIMO communication systems," IEEE Transactions on Antennas and Propagation, vol. 58, no. 1, pp. 417, 2010.

[18] Y. Tawk, M. Bkassiny, G. El-Howayek, S. K. Jayaweera, K. Avery, and C. G. Christodoulou, "Reconfigurable front-end antennas for cognitive radio applications," IET Microwaves, Antennas and Propagation, vol. 5, no. 8, pp. 985-992, 2011.

[19] B. Kim, B. Pan, S. Nikolaou, Y. S. Kim, J. Papapolymerou, and M. M. Tentzeris, "A novel single-feed circular microstrip antenna with reconfigurable polarization capability," IEEE Transactions on Antennas and Propagation, vol. 56, no. 3, pp. 630-638, 2008.

[20] S. Lee, Y. C. Lee, V. M. Bright, and K. C. Gupta, "RF-MEMS capacitive switches fabricated using printed circuit processing techniques," Journal of Microelectromechanical Systems, vol. 15, no. 6, pp. 1595-1604, 2006.

[21] D. E. Anagnostou, G. Zheng, M. T. Chryssomallis et al., "Design, fabrication, and measurements of an RF-MEMS-based selfsimilar reconfigurable antenna," IEEE Transactions on Antennas and Propagation, vol. 54, no. 2, pp. 422-432, 2006.

[22] G. M. Rebeiz and R. F. Mems, Theory, Design, and Technology, John Wiley \& Sons, New York, NY, USA, 2003.

[23] K. Entesari, K. Obeidat, A. R. Brown, and G. M. Rebeiz, "A 25-75-MHz RF MEMS tunable filter," IEEE Transactions on Microwave Theory and Techniques, vol. 55, no. 11, pp. 2399-2405, 2007.

[24] Maxim Integrated Products, "Datasheet of MAXIM5025," MAXIM, 2009.

[25] J. Kim, Cutting RF Power in W-CDMA Phone, Electronic Engineering Times, 2004.

[26] B. Behjou, B. E. Priyanto, O. K. Jensen, and T. Larsen, "Interference issues between UMTS \& WLAN in a multi-standard RF receiver," in IST Mobile Wireless Comms Summit, 2006. 

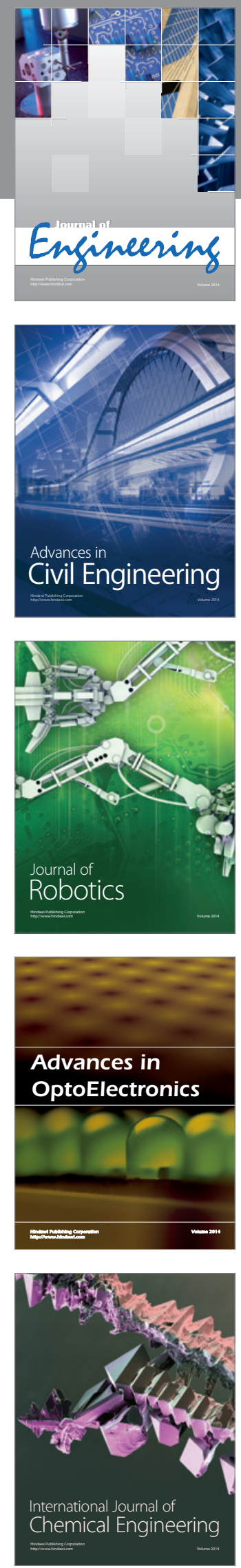

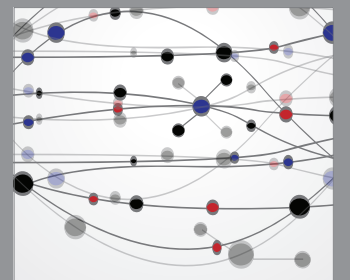

The Scientific World Journal
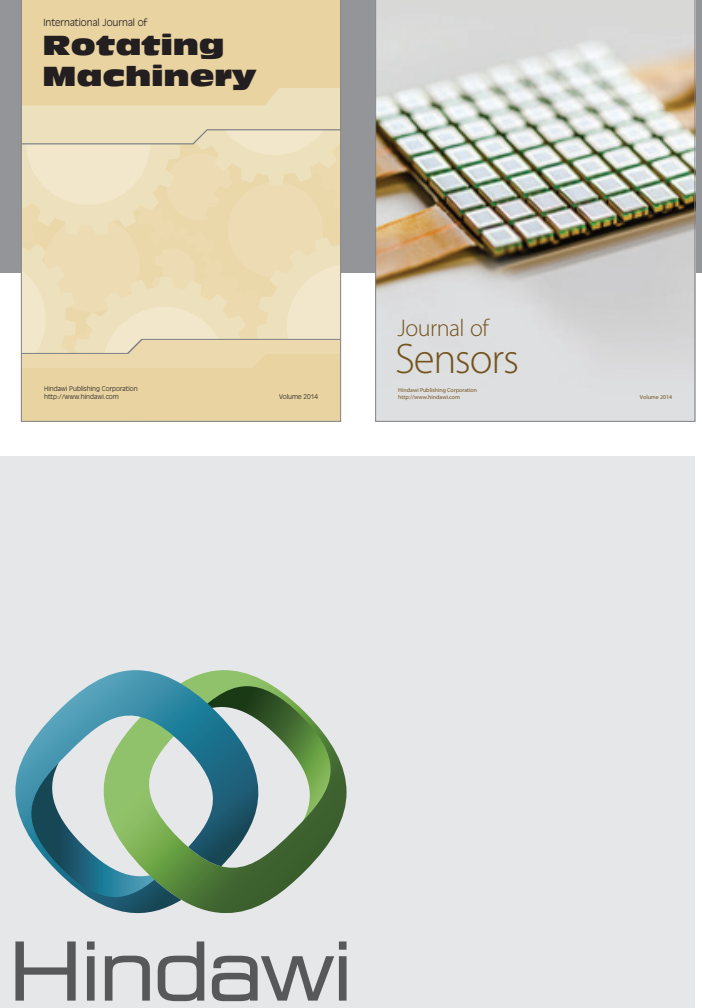

Submit your manuscripts at http://www.hindawi.com
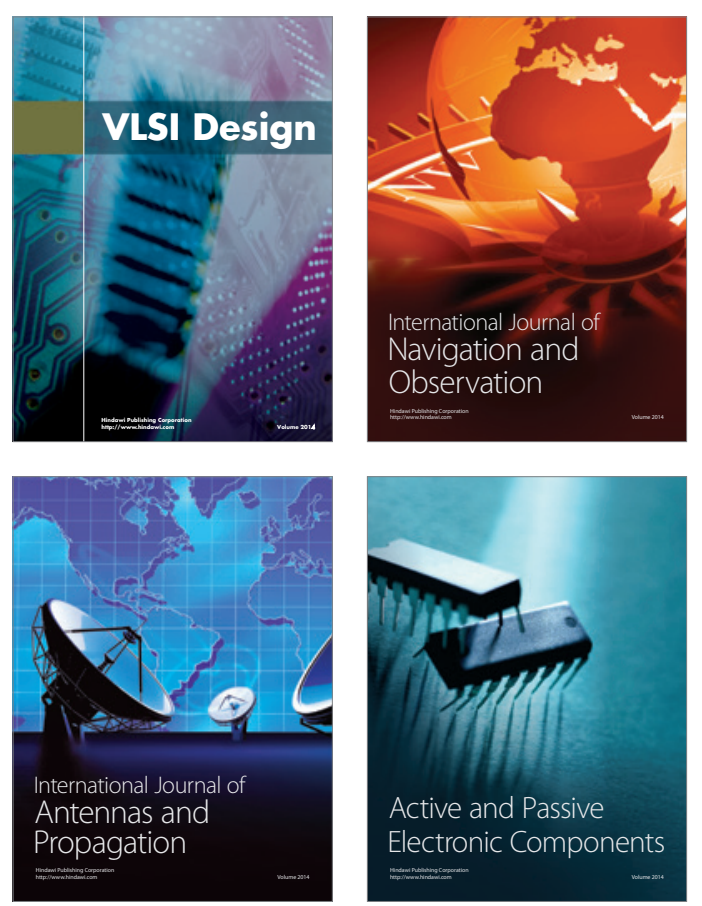
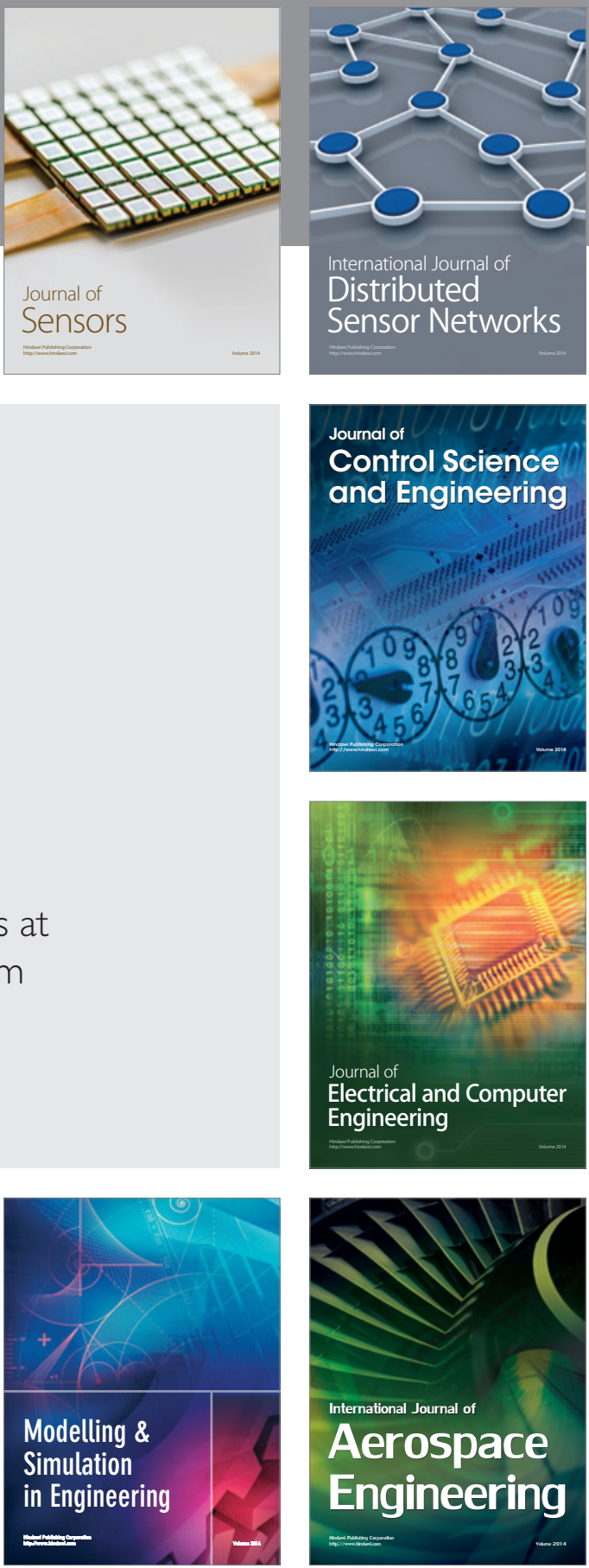

Journal of

Control Science

and Engineering
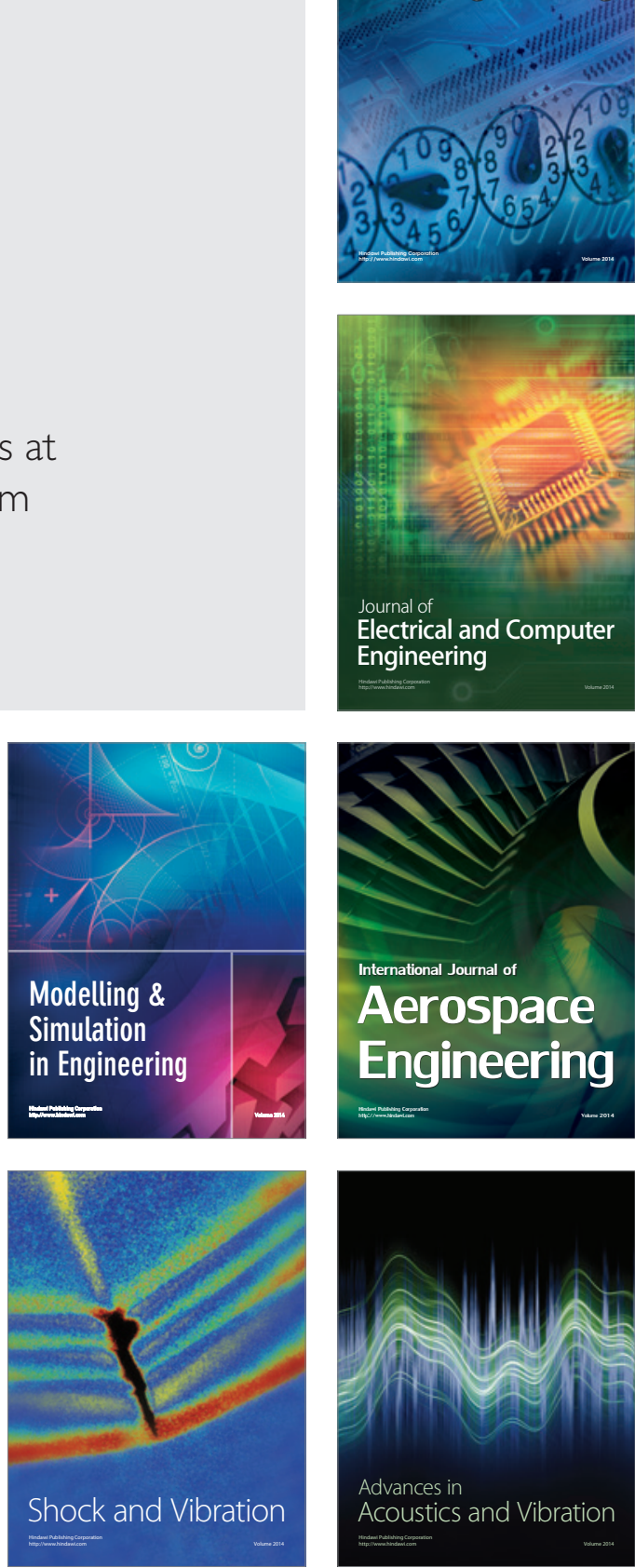